\title{
The Cerebellar Cognitive Affective/Schmahmann Syndrome: a Task Force Paper
}

\author{
Georgios P. D. Argyropoulos ${ }^{1}$ (D) - Kim van Dun $^{2}$ (D) $\cdot$ Michael Adamaszek $^{3} \cdot$ Maria Leggio $^{4,5}$ (D) Mario Manto $^{6,7}$ (D) \\ Marcella Masciullo ${ }^{8}$ (D) Marco Molinari $^{9}$ (D) Catherine J. Stoodley $^{10}$ (D) Frank Van Overwalle $^{11}$ (D) Richard B. Ivry $^{12}$. \\ Jeremy D. Schmahmann ${ }^{13}$ (I)
}

Published online: 14 September 2019

(C) The Author(s) 2019

\begin{abstract}
Sporadically advocated over the last two centuries, a cerebellar role in cognition and affect has been rigorously established in the past few decades. In the clinical domain, such progress is epitomized by the "cerebellar cognitive affective syndrome" "CCAS") or "Schmahmann syndrome." Introduced in the late 1990s, CCAS reflects a constellation of cerebellar-induced sequelae, comprising deficits in executive function, visuospatial cognition, emotion-affect, and language, over and above speech. The CCAS thus offers excellent grounds to investigate the functional topography of the cerebellum, and, ultimately, illustrate the precise mechanisms by which the cerebellum modulates cognition and affect. The primary objective of this task force paper is thus to stimulate further research in this area. After providing an up-to-date overview of the fundamental findings on cerebellar neurocognition, the paper substantiates the concept of CCAS with recent evidence from different scientific angles, promotes awareness of the CCAS as a clinical entity, and examines our current insight into the therapeutic options available. The paper finally identifies topics of divergence and outstanding questions for further research.
\end{abstract}

Keywords Cerebellum $\cdot$ Cognition $\cdot$ Emotion $\cdot$ Affect $\cdot$ Cerebellar cognitive affective syndrome $\cdot$ Schmahmann syndrome

\section{Introduction: the Cerebellar Cognitive Affective/Schmahmann Syndrome (G.P.D. Argyropoulos, K. van Dun, and M. Manto)}

A series of sporadic investigations in the last two centuries had advocated the need to revise the confinement of cerebellar (CB) function to the motor domain [1]. The rediscovery of this proposal and its systematic investigation over the last

Georgios P. D. Argyropoulos

georgios.argyropoulos@ndcn.ox.ac.uk

Kim van Dun

kimvandun@gmail.com

Michael Adamaszek

michael.adamaszek@klinik-bavaria.de

Maria Leggio

maria.leggio@uniroma1.it

Mario Manto

mmanto@ulb.ac.be

Marcella Masciullo

m.masciullo@hsantalucia.it few decades (see [2] for a review) have now firmly established a $\mathrm{CB}$ role in cognition and affect.

One of the fundamental frameworks attempting to explain these contributions was the "dysmetria of thought hypothesis" $[3-5,11]$, whereby a "universal cerebellar transform" (UCT) is applied over multiple functional domains. The proposal was predicated on: (i) the $\mathrm{CB}$ cytoarchitectural homogeneity, implying the implementation of a unitary

\author{
Marco Molinari \\ m.molinari@hsantalucia.it \\ Catherine J. Stoodley \\ stoodley@american.edu \\ Frank Van Overwalle \\ Frank.VanOverwalle@vub.ac.be \\ Richard B. Ivry \\ ivry@berkeley.edu \\ Jeremy D. Schmahmann \\ jschmahmann@mgh.harvard.edu
}

Extended author information available on the last page of the article 
computation by the cortico-nuclear microcomplex, the fundamental $\mathrm{CB}$ computational unit $[6,7]$; (ii) the functional $\mathrm{CB}$ heterogeneity, given the modular specificity of multiple cerebro-CB anatomical connections through the feedforward (cortico-ponto-CB) [8], and the feedback (CB-thalamo-cortical) limbs [9] that bring it in close interaction with supratentorial motor, paralimbic, and association cortices; (iii) the well-defined motor syndromes following damage to lobules communicating with motor and premotor cortices [10]. Disruptions of CB components of the nonmotor cerebro-CB circuits were hypothesized to deprive cognitive and affective processes from the UCT, producing an impairment in the coordination of thought, similar to the impairments in motor coordination that are the hallmark of ataxia.

Shortly following the formulation of the "dysmetria of thought" hypothesis [11], Schmahmann and Sherman reported a complex pattern of cognitive and affective deficits characterizing a group of 20 patients with focal CB lesions. This entity was termed "cerebellar cognitive affective syndrome" (CCAS) [12], also referred to as "Schmahmann syndrome" [13]. On the basis of neurological examination, bedside mental state tests, and neuropsychological assessment, CCAS was proposed to reflect a constellation of CB-induced sequelae, comprising deficits in (i) executive function: impaired working memory (e.g., deficient mental arithmetic), set-shifting, verbal fluency (manifesting as telegraphic speech, unrelated to dysarthria), problem-solving, multitasking, planning, sequencing, and organizing activities; (ii) visuospatial cognition: visuospatial disintegration (manifesting as a deficit in copying and conceptualizing drawn figures) and simultanagnosia; (iii) language, over and above speech: agrammatism, mild anomia, and dysprosodia; and (iv) emotion-affect: flattening of affect or disinhibition (often manifesting as humorous yet inappropriate comments, impulsive actions, and overfamiliarity), regressive and childlike behavior in some patients and obsessive-compulsive traits in others, and pathological laughing and crying [12]. Further insight has more recently been gained from a neuropsychiatric perspective by the identification of five core features: deficits in attentional or emotional control, autism or psychosis spectrum symptoms, and deficient social skills. The symptoms within each domain were conceptualized as reflecting either exaggerated-hypermetric or diminished-hypometric responses to the internal and/ or external environment [14].

Overall, these symptoms were attributed to disruptions of pathways reciprocally connecting the $\mathrm{CB}$ with limbic circuitry and prefrontal, temporal, and parietal association cortices. More specifically, the deficits in linguistic, visuospatial, and executive function were held to result from the disrupted connectivity between the posterior
$\mathrm{CB}$ lobe (the medial and hemispheric regions of lobule VIIA Crus I/II, but also HVI and HVIIB) and cerebral association areas, especially prefrontal cortical areas in relation to executive control, parietal cortical areas with respect to visuospatial function, and frontotemporal regions in relation to linguistic function. Affectiveemotional disturbance was seen as associated with lesions in the "limbic cerebellum," associated with the vermis and fastigial nuclei connections with the reticular nuclei in the brainstem, intralaminar and anterior thalamic nuclei, the hypothalamus, as well as with the hippocampus, septum, amygdala, ventral tegmental area, periaqueductal gray and mammillary bodies, cingulate gyrus, and pregenual, retrosplenial, and paralimbic neocortical regions (for references, see [12, 14]).

The CCAS thus provided the concrete, clinical entity that lent support to the "dysmetria of thought" hypothesis and, more general, to a CB role in cognition and affect. As such, CCAS has been conceptualized as representing the third cornerstone of clinical ataxiology, the other two being the longer-established "cerebellar motor" and "vestibulo-cerebellar" syndromes [15].

As the question of relevance today no longer pertains to whether the CB plays a role in cognition and affect, but to the mechanisms by which this is accomplished [2], we hold that CCAS provides an ideal clinical entity for such an enterprise. This task force paper thus focuses on CCAS, reviewing its foundations, promoting awareness of its core components, tackling the skepticism articulated on its premises and relevant findings, discussing our current insight into its treatment, and identifying outstanding questions and future directions.

To this end, we have gathered contributions from experts in $\mathrm{CB}$ neurocognition. The section "Cerebellar Functional Topography in CCAS: Updates and Challenges" (Argyropoulos and Ivry) provides a critical introduction to $\mathrm{CB}$ functional topography, and the section "Cerebellar Neurocognition: Relevance to CCAS" (Stoodley and Van Overwalle) summarizes the neuroimaging evidence for a $\mathrm{CB}$ role in multiple cognitive domains in relation to CCAS. In the "Introducing Cognition into Cerebellar Rehabilitation: Facts and Hopes" section, Adamaszek, Masciullo, and Molinari address the practical issues pertaining to the multimodal deficits in CCAS and reflect on the current insight on therapeutic options. In the "Replication of CCAS" section, Schmahmann and Leggio review the replication of the CCAS over the past two decades in adults and children with inherited and acquired $\mathrm{CB}$ diseases. Finally, the "Discussion: Consensus on CCAS and Future Directions" section (Argyropoulos, van Dun, and Ivry) summarizes the points of convergence of the different sections and identifies outstanding questions that require further investigation. 


\section{Cerebellar Functional Topography in CCAS: Updates and Challenges (G.P.D. Argyropoulos and R.B. Ivry)}

\section{Introduction}

Recognition of the impact of CB dysfunction across multiple task domains has accumulated over the last 30 years. Lesionbehavior relationships have been investigated with patient [16-18] and noninvasive brain stimulation studies [19]. Correlational evidence has come from neuroimaging studies, primarily involving either task-based fMRI [20-22] or resting-state functional connectivity [23-25]. Coupled with anatomical and physiological investigations in animal models $[26,27]$, these studies have helped develop a picture of $\mathrm{CB}$ functional topography, providing insight into the specific deficits in CCAS. In this section, we provide an overview of this topography and outline future research questions for CCAS.

\section{Basics of Cerebellar Functional Topography}

CB functional topography is often seen in a quadripartite distinction of gross functional regions: the "vestibular," "motor," "cognitive," and "limbic cerebellum" [10, 15]. Despite the considerable variation in the strength of the evidence, the literature indicates that distinct syndromes are associated with damage to these regions (e.g., $[17,28]$ ).

\section{The "Vestibular" and "Motor Cerebellum"}

The vestibular CB comprises the flocculus-paraflocculus, the nodulus-ventral uvula (lobules IX and $\mathrm{X}^{1}$ ), and the oculomotor vermis (V-VII), with much of the output of these regions constituting the fastigial oculomotor region. The flocculonodular lobe $(\mathrm{X})$ receives afferent projections from the vestibular nuclei. The vestibulo-CB syndrome is characterized by deficits of oculomotor movements, ocular misalignment, and instability [15].

Regarding the "motor cerebellum," a broad range of studies, from physiological investigations in cats [31-33] to fMRI studies in humans [21, 34], have delineated at least two somatotopic CB representations $[33,35,36]$ : a primary sensorimotor region (anterior lobe and adjacent VI) and a secondary region (lobule VIII). Tract-tracing in monkeys has

\footnotetext{
${ }^{1}$ The CB cortex comprises ten lobules; the anterior lobe is formed of lobules $\mathrm{I}-\mathrm{V}$; the posterior lobe comprises lobules VI-IX; lobule $\mathrm{X}$ is identified as the flocculonodular lobe. We follow the nomenclature in the "MRI Atlas of the Human Cerebellum" [29]: CB lobules are labeled "I-X" from the anteriorsuperior border, through posterior-superior, posterior-inferior, to the anteriorinferior border. The nomenclature is based on that of Larsell and Jansen [30]hemispheres are distinguished from the vermis with the " $\mathrm{H}$ " prefix. The atlas of Schmahmann and colleagues [29] uses this prefix to refer to the hemispheres, and the adjective "vermal" to refer to vermal compartments of a lobule. No prefix is used when referring to the entire lobule.
}

established reciprocal connectivity between the primary motor cortex and lobules V, VI, VIIB, and VIII $[1,2]$ through feedforward corticopontine projections [37] and feedback projections via the interposed and dorsal dentate nuclei and thalamus [38]. Likewise, hemodynamic activity in human sensorimotor cortical regions correlates with that in the contralateral CB anterior lobe, the adjacent VI, and VIII [23-25, 39]. Hand, foot, and tongue movement activates the same lobules [21, 22, 40-44].

The CB motor syndrome is characterized by disequilibrium, ataxic gait, impaired limb coordination, and dysarthria. Upper limb ataxia is associated with lesions in the anterior lobe, adjacent regions of lobule VI, the interposed nuclei, and the dorsal dentate [17, 28, 42, 45-47]. Likewise, dysarthria is linked to damage in vermal VI (sensorimotor representation of the articulatory apparatus [48]), paravermal V-VI, and the dentate nucleus [49-51]. Detailed somatotopic evidence is shown in a large lesion-symptom ${ }^{2}$ mapping study [45] (Fig. 1). It remains unknown how damage restricted to posterior motor regions impacts movement. Damage there is less consistently associated with impaired motor learning as compared to anterior motor regions [53] and may not show lasting motor deficits [45].

\section{The "Cognitive and Limbic" Cerebellum}

Cognitive functions are associated with much of the posterior lobe (HVI, (H)VIIA Crus I/II, HVIIB, and (H)IX). In monkeys, polysynaptic pathways connect area 46 with Crus I/II and IX [38], and pontine input arises from frontopolar area 10 through to the most posterior regions of area 8 [8]. Moreover, the principal olive is linked with the lateral $\mathrm{CB}$ and the dentate nucleus (see[85, 281]). The likely anatomical substrate supporting a CB influence on autonomic/affective/limbic-related behavior is the connectivity of the vermis and the fastigial nucleus with subcortical limbic areas, associative and paralimbic cortical regions (see [27] for review). There is also evidence for anterior cingulate projections to medial Crus I and II [32]. Physiologically, vermal stimulation has been shown to modulate hippocampal, amygdala, and septum firing patterns [55].

Cortical-CB connectivity has been studied in humans with resting-state functional connectivity studies, investigating multiple $\mathrm{CB}$ networks, similar to those in the cerebral cortex. The networks in neo-CB regions are associated with prefrontal, posterior parietal, middle/superior temporal association cortex, as well as limbic and paralimbic regions [23-25, 39]. Nevertheless, there is little evidence

\footnotetext{
${ }^{2}$ The term "lesion-symptom mapping" is used to denote a broader range of methods used to investigate the relationship between symptoms and lesions, not necessarily in a voxel-based fashion, whereas the term "voxel-based lesion-symptom mapping" ("VLSM") is reserved for the subset of these methods employing a voxel-based approach.
} 
to date to suggest a segregation of neo-CB regions in terms of functional connectivity with limbic versus association cortices.

In task-based fMRI studies, activations related to cognitive processes are typically observed in VI, Crus I/II, and IX. Similar regions are activated in contrasts designed to identify cognitive control processes [20,21]. Studies of affective processing also disclose $\mathrm{CB}$ activation, albeit in both hemispheric and medial regions (HIV-HVI, HVIIA Crus I/II, X, vermal Crus II $[20-22,56])$.

\section{Relating Function to Structure in Cerebellar Disease}

CCAS, by definition, postulates that impairments in cognitive and affective function are associated with $\mathrm{CB}$ damage. Much of this literature has involved the use of standard instruments to provide a neuropsychological profile in different patient populations (e.g., genetic subtypes, focal lesions, developmental abnormalities). In terms of cognition, the picture is somewhat contentious, with considerable variation across studies. In general, patients perform within normal bounds on perceptual and memory tests. Impairments, when observed, are on tests designed to assess executive function, similar to what is observed in patients with prefrontal lesions, although the impairments are generally milder [57]. The affective component of CCAS is assessed in a less systematized fashion, with many studies primarily employing clinical psychiatric assessment, with psychopathological diagnoses based on DSM $[58,59]$. Our understanding of $\mathrm{CB}$ contributions to affect will be strengthened by more comprehensive employment of appropriate neuropsychological tests in larger patient samples (e.g., [13]).

Given the CB functional compartmentalization, patient data can be used to examine the correspondence between symptoms and lesion location. Much of this work has been based on case studies, but a few groups have undertaken larger-scale studies, employing more sophisticated statistical tools. Such investigations associate motor impairment with damage in the anterior lobe extending to VI and cognitive dysfunction with posterior CB damage ("Cerebellar Neurocognition: Relevance to CCAS" section).

The affective component of CCAS has been associated with damage in the posterior vermis and the fastigial nucleus $[12,58-60]$. In the initial report of CCAS [12], the changes in affect in individuals with acquired CB lesions tended to resolve with time, suggesting that the affective changes may be due to remote disturbance in other regions. However, individuals with abnormal midline $\mathrm{CB}$ development show persistent changes in affect, but also cognitive impairment, even if the pathology is restricted to the vermis [58]. To date, there has been minimal sophisticated lesion-symptom mapping in the affective domain. One exception is a recent voxel-based study by Kim and colleagues [61], where left posterior CB damage
Fig. 1 Highlights of advances in CB motor topography made by VLSM. a-f Lesion-symptom mapping analysis for subscores of the International Cooperative Ataxia Rating Scale (ICARS) [52] in patients with acute ischemia. a Upper limb ataxia correlated with lesions in vermal, paravermal, and hemispheric IV-VI. b Lower limb ataxia correlated with lesions in vermal, paravermal, and hemispheric III-VI. Limb ataxia correlated with lesions in the interposed and parts of the dentate nuclei; ataxia of gait (c), posture (d), and trunk (e) correlated with lesions in vermal and paravermal II-IV and lesions in the fastigial and interposed nuclei. f Dysarthria correlated with lesions in paravermal and hemispheric V-VI. Figures adapted from [45] @ 2005, with permission from Elsevier

was associated with depressive mood severity in 24 patients with isolated CB stroke (Fig. 2).

\section{Challenges and Future Directions}

Considerable progress has been made in CB functional topography, which, coupled with the extensive neuropsychological literature, provides a firm foundation for understanding the pathology of CCAS and the symptom-lesion relationships of this syndrome.

\section{Beyond Lobe- and Lobule-Based Lesion-Symptom Mapping}

To date, the majority of lesion-symptom mapping studies have involved relatively crude grouping divisions: patients may be clustered as "vermal versus hemispheric," "posterior versus anterior lobe," or based on a simple lobular scheme [16, 28, $60,62,63]$. Relatively few (e.g., [17, 45]) have used more sophisticated methods, such as voxel-based lesion-symptom mapping (VLSM) [64], in which MRI data are transformed onto standard atlases to allow inferential statistics based on voxel overlap, in part because these studies require relatively large samples. These approaches offer great promise for developing a refined picture of lesion-symptom mapping [65], one that can help shift the field away from its traditional lobeor lobule-based perspective, incorporate the amplified sequelae of lesions in deep CB nuclei (e.g., [45]), and examine intraand cross-lobular functional regions, since resting-state networks do not conform to lobular boundaries [24].

Structure-behavior mapping methods can be employed with diverse populations, including patients with degenerative disorders, stroke, and tumor. They offer a powerful tool to understand $\mathrm{CB}$ contributions to different developmental and psychiatric conditions, since $\mathrm{CB}$ hypoplasia is correlated with a number of those (e.g., autism, ADHD, schizophrenia, fragile X syndrome). Here, we have the opportunity to explore the specificity of impairments associated with early $\mathrm{CB}$ abnormalities, but also look at compensatory effects. Nevertheless, it will be important to not limit these studies to an analysis of CB dysfunction; in many conditions, pathology extends into the brainstem, diencephalon, and cerebral cortex. To date, we are not aware of any studies that have asked how the behavioral 

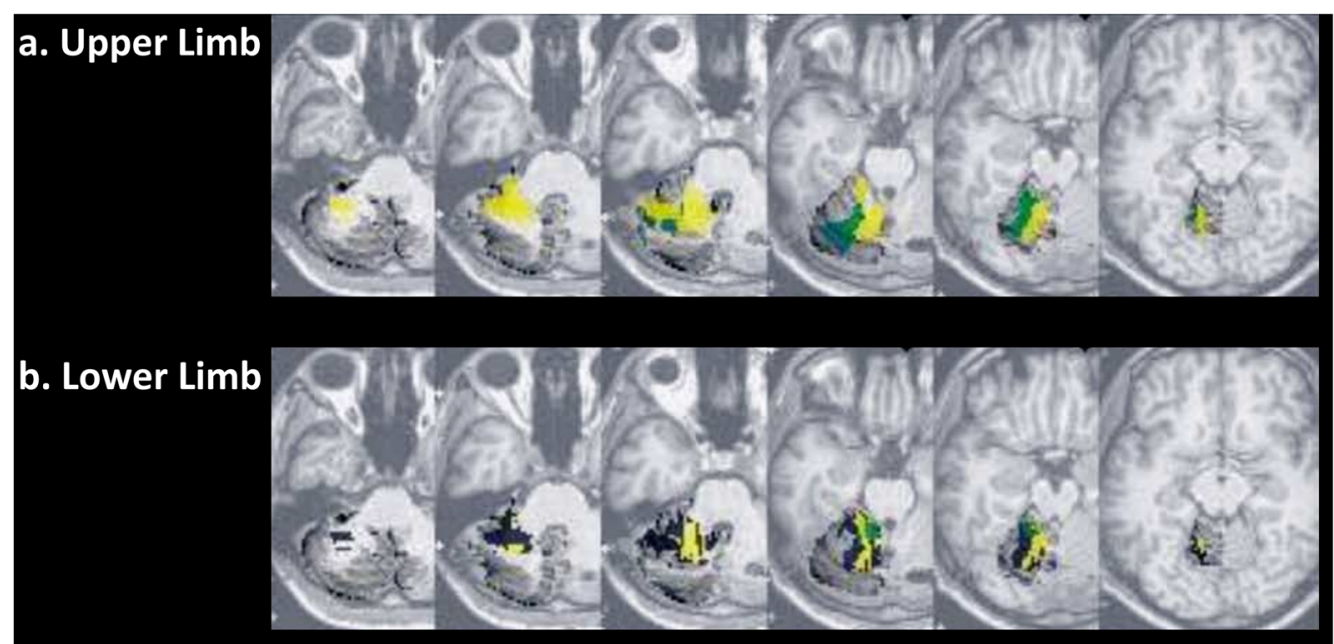

c. Gait

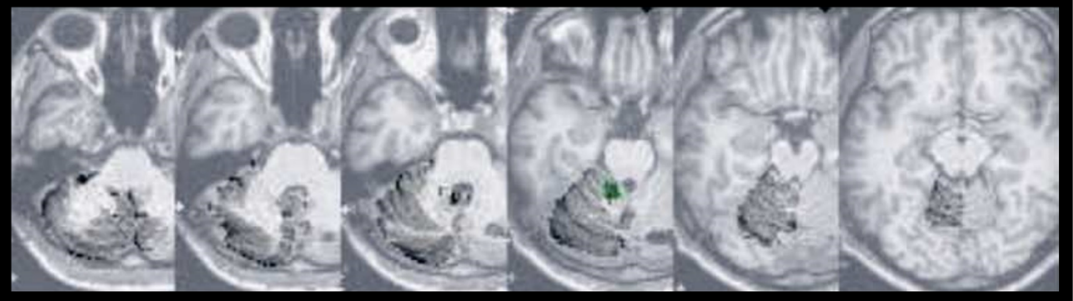

\section{d. Posture}

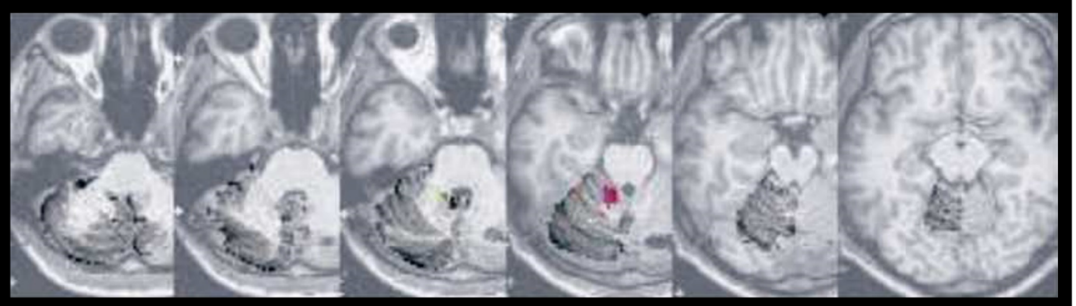

e. Trunk

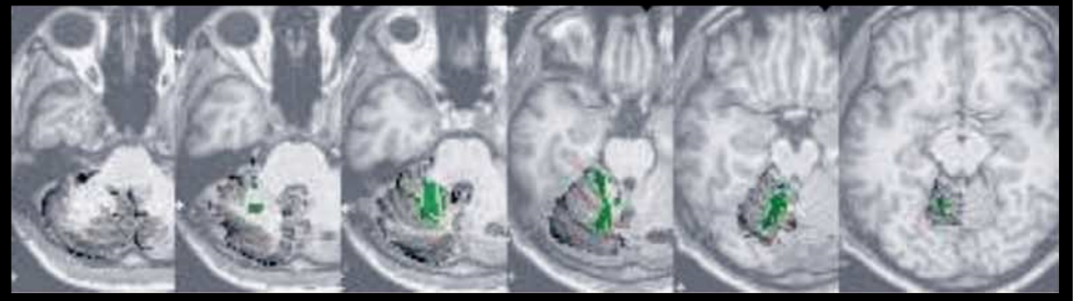

\section{f. Speech}

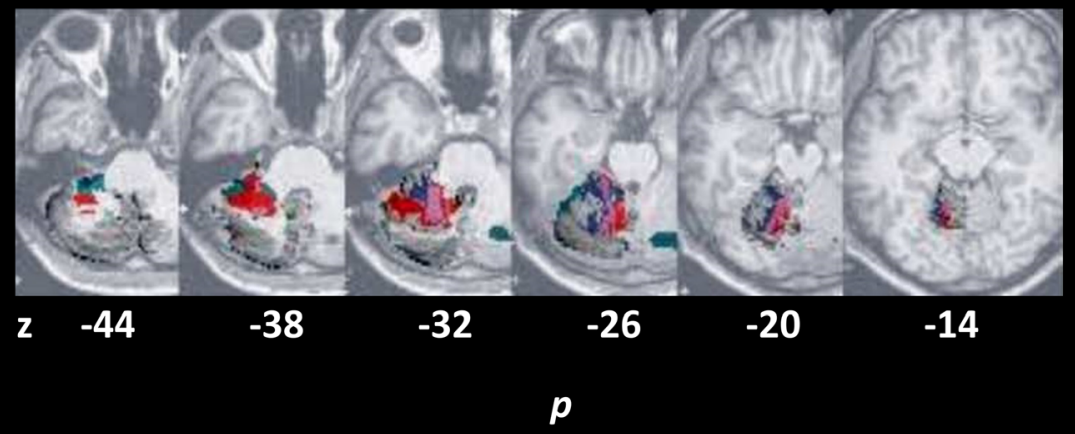

0.05

0.001

0.0001

1.3

0.01

3

4

5

6

$-\log (p)$ 


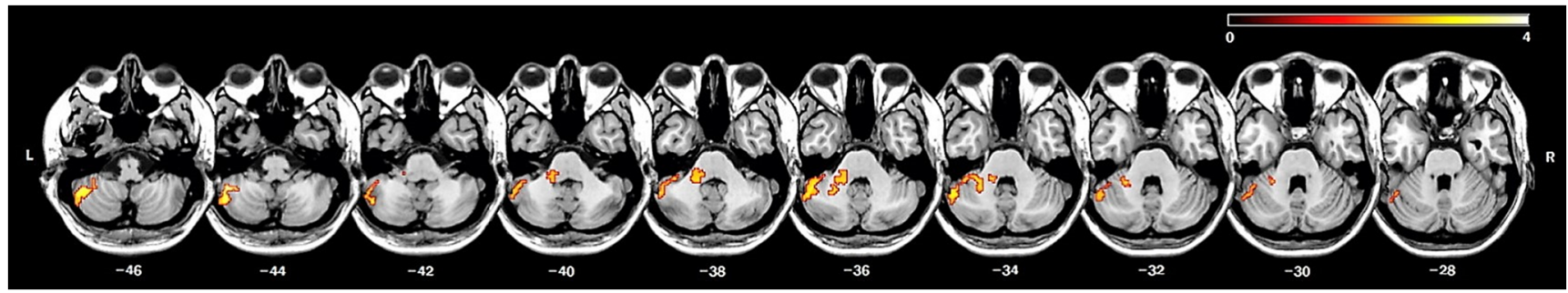

Fig. 2 CB VLSM on depressive symptom severity. Figure adapted from [61] @ 2017, with permission from Elsevier

consequences of damage to a particular $\mathrm{CB}$ region are modulated by correlated pathology in extra-CB structures.

\section{Beyond the Cerebellum}

This last point is also relevant when considering CCAS, even in focal $\mathrm{CB}$ pathology. One feature of the original paper linking affective disturbances to $\mathrm{CB}$ pathology is that the symptoms were transient in many patients [12]. Subsequent work has shown that affective changes can be chronic, observed in patients with spinocerebellar ataxias (SCAs) [66] or adult survivors of childhood CB insults [63]. Understanding the time course of different clusters of symptoms can provide important clues concerning whether symptoms arise directly from disruption of $\mathrm{CB}$ processing or indirectly from off-target effects [67].

More generally, a network-based approach is essential for understanding $\mathrm{CB}$ function across domains. CCAS involves deficits similar to those following lesions in the cerebral nodes of the corresponding cerebro-CB loops [12]. Likewise, recent work suggests that deficits traditionally associated with basal ganglia (BG) pathology such as dystonia may actually reflect disruption of $\mathrm{CB}-\mathrm{BG}$ interactions [68], a point underscored by evidence of reciprocal, multimodular $\mathrm{CB}-\mathrm{BG}$ connectivity [69-71]. Future research should examine CB contributions on cognitive processes traditionally associated with the BG, such as probabilistic learning or reinforcement. Not only will this work help sharpen our description of CCAS, but the study of patients with acute lesions can be used to ask if CB pathology disrupts BG function.

A network perspective is also warranted to reconsider memory function and the $\mathrm{CB}$, in light of the default-mode network hubs in posterior Crus I/II and IX [24]. To date, hippocampal-CB connectivity [72-75, 282] is primarily discussed with respect to a CB role in affect $[12,27]$, but not in relation to prominent hippocampal functions, i.e., episodic memory and navigation [76], despite the evidence supporting $\mathrm{CB}$ involvement in navigation $[77,78]$ and episodic memory $[79,80]$. Interestingly, a meta-analytic study on neurodegenerative conditions disclosed CB atrophy in Alzheimer's disease (right HVI/HVIIA Crus I/II [81]), which was discussed in relation to $\mathrm{CB}$-hippocampal functional connectivity [82]. Here, too, would be an opportunity to explore cognitive deficits in Alzheimer's disease as a function of the extent of CB pathology.

\section{Beyond Heuristic Labels}

Finally, it is important to recognize that functional labels ("cognitive," "language," "executive," "affect") are just heuristics and that applying such labels may impede our understanding of computational principles. For instance, anatomical, functional, and symptom-based analyses converge on the idea of two CB motor zones: an anterior one (lobules I-VI) and a more posterior one (lobule VIII). While the role of the latter deserves further investigation, data also implicate damage to lobule IX in upper limb dysfunction [17, 83]. This region may be essential for the visual guidance of movement [84], given its connections with visual association areas [85]. Thus, we may need to revise our methods for differentiating "motor" from "cognitive," open to the idea that CB function may require considering an interface between higher-level functions and motor-like operations. For example, the internalization of speech mechanisms in covert rehearsal is an important part of verbal working memory [86] ("Cerebellar Neurocognition: Relevance to CCAS” section).

\section{Conclusion}

We provided an overview of $\mathrm{CB}$ functional topography in relation to CCAS, highlighting some of the gaps in this literature, in terms of $\mathrm{CB}$ regions and their interactions with extra$\mathrm{CB}$ structures. Our understanding of CCAS and $\mathrm{CB}$ function will benefit from more rigorous work using VLSM. Here is an ideal situation to develop multisite collaborations, since the sensitivity of these studies is greatly improved with large samples.

\section{Cerebellar Neurocognition: Relevance to CCAS (C. Stoodley and F. Van Overwalle)}

\section{Introduction}

Data from multiple sources support a role for the human $\mathrm{CB}$ in cognitive function. Understanding the specific $\mathrm{CB}$ regions 
that support cognition and the $\mathrm{CB}$ contribution to cognitive functions are relevant to our understanding of the CCAS. Drawing upon evidence from healthy populations and studies of CB patients, we summarize the neuroimaging evidence that the $\mathrm{CB}$ supports cognition in multiple domains, the relevance of such findings to understanding cognitive deficits in $\mathrm{CB}$ patients, and the theoretical constructs of what the $\mathrm{CB}$ might contribute to cognitive function.

\section{Cerebellum and Cognition: Evidence from Neuroimaging}

Neuroimaging studies in healthy individuals consistently report $\mathrm{CB}$ activation during a wide range of cognitive tasks (for reviews, see $[20,21,87])$, consistent with the idea that the $\mathrm{CB}$ is part of a network of regions supporting cognitive function. Resting-state fMRI studies demonstrate CB functional connectivity with cerebral cortical regions involved in cognitive processes (e.g., the prefrontal cortex [25]), and more broadly with the frontoparietal, dorsal/ventral attention, and mentalizing/default networks (e.g., [24]). Within the CB, there is a broad distinction between regions that are engaged during sensorimotor tasks and show functional connectivity with primary motor and somatosensory cortices (anterior lobe extending into medial lobule VI and lobule VIII) and regions showing activation during cognitive tasks and functional connectivity with frontal and parietal regions (posterolateral CB; Fig. 3). Neuromodulation of the posterolateral CB has been shown to impact functional connectivity with prefrontal and parietal networks, with no effect on functional connectivity with sensorimotor regions (e.g., $[89,90])$, which is consistent with the anatomical connections between the $\mathrm{CB}$ and cerebral cortices (see $[26,91]$ ).

The $\mathrm{CB}$ is active during functional localizers for language and is considered part of language networks ([92]; see [93] for a consensus paper). A variety of language and reading tasks, including verbal fluency, verb generation, and sentence completion, engage the $\mathrm{CB}$ (see [87] for review), and $\mathrm{CB}$ neuromodulation impacts performance on similar paradigms (e.g., [94-96]). The predominantly left-lateralized cerebral cortical activation during language paradigms is mirrored by right-lateralized posterolateral $\mathrm{CB}$ activation, reflecting the contralateral connectivity between the $\mathrm{CB}$ and cerebral cortex (see [97]). Notably, anterior and medial CB regions are

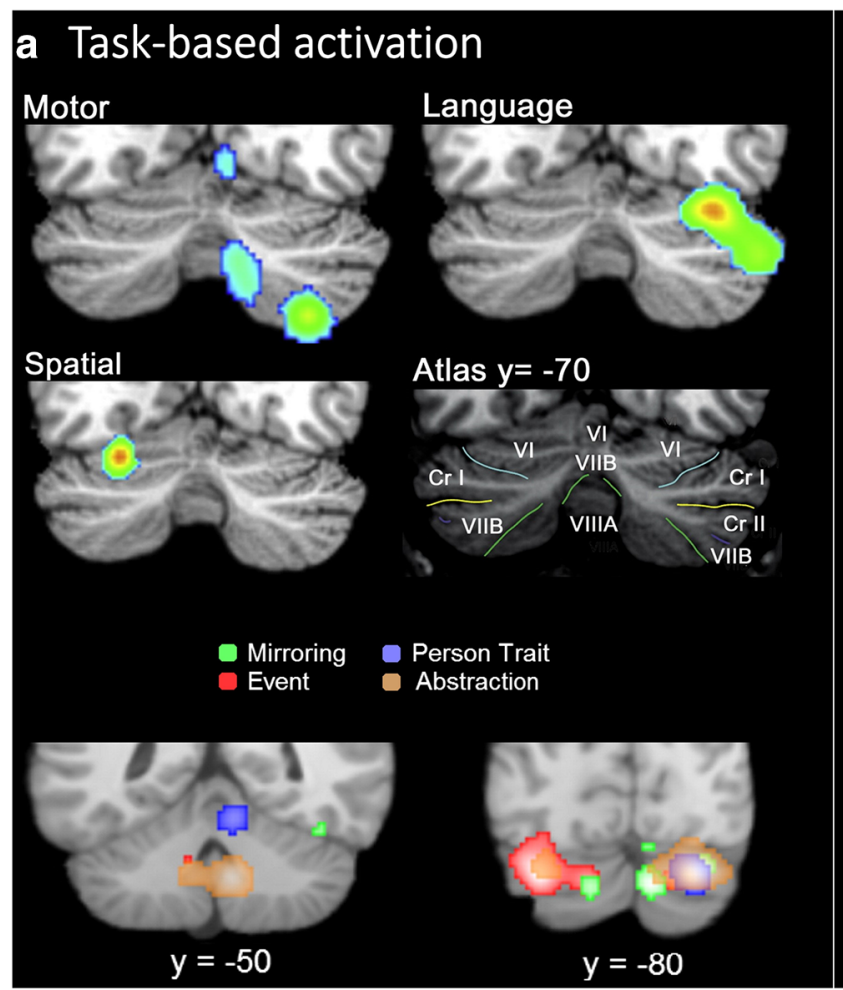

Fig. $3 \mathrm{CB}$ engagement in cognitive tasks and cerebro-CB networks supporting cognition. a (Top) A meta-analysis of task-based activation patterns reveals $\mathrm{CB}$ activation during language and spatial tasks differs from $\mathrm{CB}$ regions engaged during motor tasks (modified from [21], with permission). (Bottom) A meta-analysis of task-based activation patterns reveals $\mathrm{CB}$ activation during social mirror-related tasks (mirroring) and social mentalizing-related tasks (inferring intentions behind events, personality traits, and more abstract inferences including a person's past

\section{b Resting-state functional connectivity}
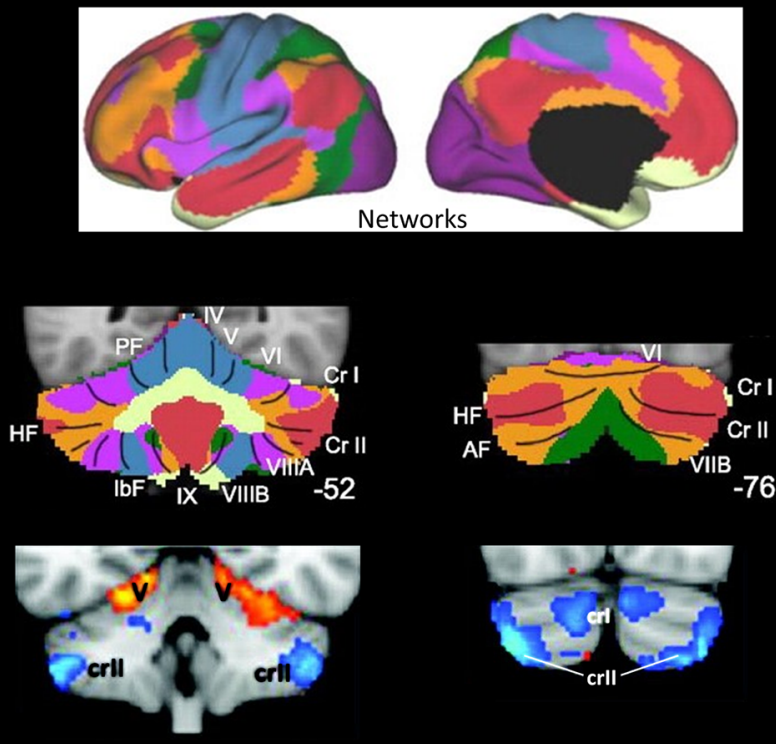

Correlations with cerebral cortex masks

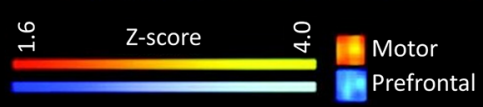

and future) (modified from [88],with permission). b (Top) Resting-state functional connectivity shows that the $\mathrm{CB}$ is part of resting-state networks supporting cognition, including the frontoparietal control network (orange) and dorsal (green) and ventral (violet) attention networks (modified from [24], with permission). (Bottom) A similar pattern is seen when $\mathrm{CB}$ functional connectivity with motor (orange) and prefrontal (blue) masks are used (modified from [25], with permission) 
engaged during articulation, whereas cognitive linguistic task activation is more posterior and lateral [97], reinforcing the idea that $\mathrm{CB}$ contributions to cognition are not contingent on overt motor control.

Working memory, spatial, and executive function tasks also engage $\mathrm{CB}$ circuits. Working memory paradigms, such as the n-back and Sternberg tasks, activate lobule VII bilaterally and right VIII; spatial tasks, including mental rotation and line bisection, engage bilateral lobule VI; and executive function paradigms, such as the Wisconsin Card Sorting Task, also involve bilateral CB regions, predominantly lobule VII (see $[20,21])$. Meta-analyses show that there are both distinct and overlapping CB regions involved across these tasks [20, 21], depending on task demands. For example, within subjects, activation associated with verbal working memory overlaps in right lobule VII with activation during covert verb generation (e.g., [43]), reflecting shared linguistic components of these tasks. In a large sample from the Human Connectome Project, a recent study investigated CB activation patterns for working memory, language, social processing, and emotion processing [22] and showed largely distinct activation patterns associated with different cognitive measures and revealed cognitive task activation in lobules IX/X in addition to VI and VII.

More recently, the $\mathrm{CB}$ role in social cognition has gained increasing recognition. A meta-analysis $([88,98])$ showed that about one third of all studies on social cognition engaged the $\mathrm{CB}$ when the tasks involved social mirroring (e.g., observing others' intentional body movements) or mentalizing (e.g., inferring others' intentions, beliefs, and personality traits on the basis of behavioral descriptions; Fig. 3). Roughly, the mirror versus mentalizing tasks follow the same anterior sensorimotor versus posterior nonmotor distinction in the CB. Functional connectivity analyses on social cognition confirmed task-related connectivity between the anterior $\mathrm{CB}$ and activation in mirror cortical areas, while the posterior $\mathrm{CB}$ (mainly Crus I) showed task-related connectivity with cortical areas involved in mentalizing $[99,100]$. Further, a recent repetitive transcranial magnetic stimulation (rTMS) study found that CB rTMS interfered with implicit social biases [101].

\section{Relationship to CCAS: Do Patient Outcomes Reflect Imaging Patterns Seen in Healthy Individuals?}

Findings from neuroimaging studies in healthy individuals suggest that cognitive deficits should result from damage or degeneration involving posterior $\mathrm{CB}$ regions. Indeed, in its very first description, it was noted that the CCAS tends to result from lesions affecting the posterior CB lobe [12]. Evidence from pediatric $\mathrm{CB}$ damage and developmental disorders also suggests that the anterior "motor" versus posterior "cognitive" dichotomy is present early in development and predicts later outcomes (for review, see [102]). VLSM in CB stroke patients showed that the $\mathrm{CB}$ motor syndrome was associated with anterior $\mathrm{CB}$ lesions, whereas CCAS resulted from posterior CB damage [17]. Consistent with task-based functional imaging, worse motor symptoms (pegboard, tapping, ataxia scores) resulted from lesions to the anterior lobe, whereas impaired language performance (e.g., Boston Naming Test) was associated with right-lateralized damage to lobule VII (Fig. 4). Among the cognitive tasks, there was also variation in the $\mathrm{CB}$ regions where damage resulted in poorer task performance; for example, performance on the Wisconsin Card Sorting Task was associated with damage to lobules VII and VIII, whereas poorer performance on Trails A and B was associated with lesions involving lobules IV-VI. These findings are consistent with neuroimaging activation patterns in healthy individuals.

SCA patients also show an association between the posterior lobe and cognitive performance. Kansal and colleagues reported that cognitive scores in CB degeneration (e.g., verb and phonemic fluency, working memory, cognitive flexibility) were associated with the volume of posterior lobe regions, including lobules VI, VII (Crus I, Crus II, and VIIB), and IX [80]. In aging populations, similar relationships were seen between posterior CB volumes (e.g., Crus II, VIIB) and cognitive function [103]. Functional connectivity analyses support these structural imaging findings: in SCA2, lobules VI and VII showed reduced functional connectivity with cortical

\section{Motor: Ataxia scale}
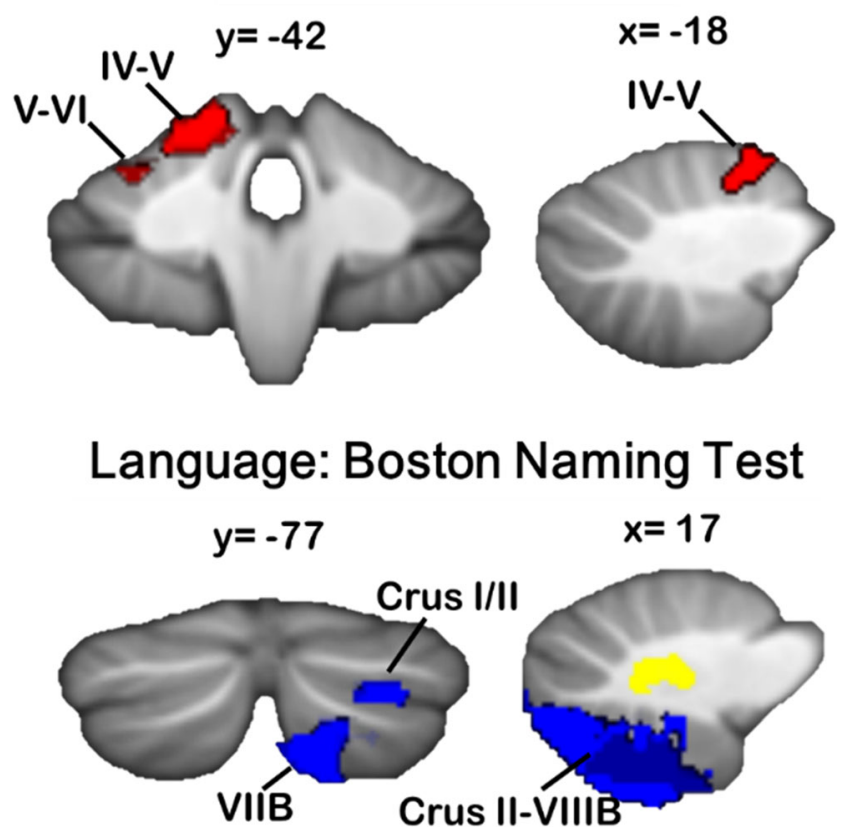

Fig. 4 VLSM reveals $C B$ regions associated with cognitive versus motor deficits following CB stroke. Significantly poorer ataxia symptoms were associated with damage to the anterior CB and lobule VI (top), whereas poorer performance on the Boston Naming Test was associated with right-lateralized damage to posterior $\mathrm{CB}$ regions, including Crus II, VIIB, and VIII (bottom). Adapted with permission from [17] 
regions supporting cognition and emotion, including the superior and middle frontal gyri [104]. Such changes in cerebro$\mathrm{CB}$ network connectivity have also been associated with clinical impairments in visual-spatial processing and executive function in SCA6 [105].

In social/emotional cognition, patients with $\mathrm{CB}$ disorders show impairments in attributing facial expression to the correct emotional or mental state [106-109]; for a review, see [110]). With respect to understanding social behavior, several studies reported that $\mathrm{CB}$ patients have impairments in identifying or generating a plausible sequence of pictures reflecting a complex action performed by a human agent $[111,112]$. Patients were particularly impaired when correct sequencing required mentalizing about the agents' beliefs, but not so for routine social scripts [113]. Likewise, Zalla and colleagues $[114,115]$ found that children with autism spectrum disorder (ASD) were impaired in predicting the outcome or sequence of human behavior, but were less impaired in understanding routine social interactions. Indeed, there are strong associations between CB dysfunction and ASD (for reviews, see [116-118]). Studies have reported altered connectivity between the CB and cortical areas in ASD [119, 120], and CB gray matter volume correlates with the degree of social impairment in ASD (e.g., [121]).

As both functional neuroimaging and lesion-mapping studies increase in number, $\mathrm{CB}$ regions associated with more specific aspects of cognition will likely emerge, leading to improved prediction of cognitive outcomes in $\mathrm{CB}$ patients.

\section{Which Aspects of Cognition Does the Cerebellum Support?}

It has been proposed that the relatively uniform $\mathrm{CB}$ circuitry supports a common processing mechanism (e.g., [26, 122, 123]), the UCT [3]. The CB is thought to build motor or mental internal models [124], which are trained based on error signals and used to predict the consequences of ongoing motor or mental processes [122]. This enables the $\mathrm{CB}$ to participate in processes important to optimal cognitive function, including prediction [125] and performance monitoring [126]. In cognition, prediction has most often been studied in the context of language (see reviews in $[127,128])$. For example, CB neuromodulation disrupted performance when the first part of a sentence generated a strong prediction, but not when sentences did not have a strong predictive context $[95,96]$. Neuroimaging studies have shown CB activation associated with linguistic predictions [90, 129, 130] and violations of those predictions $[129,130]$ during sentence processing. However, imaging or stimulation studies that explore the mechanisms underlying impaired social action sequencing and their implications are lacking.

Now that the CCAS has been described in multiple CB patient populations and its neural correlates are starting to be delineated, the field can focus on establishing a better understanding of which aspects of cognition are impaired in $\mathrm{CB}$ disease. This will entail designing measures that tap specific features of cognitive processes (e.g., error monitoring, prediction, sequencing) to determine whether a common mechanism can be identified that, when damaged, leads to the deficits seen in $\mathrm{CB}$ patients.

\section{Conclusion}

Evidence from neuroimaging and patient populations suggests that the posterolateral $\mathrm{CB}$ contributes to cognitive processing via anatomical connections with supratentorial regions supporting cognitive function. Future investigations should aim to clarify the effects of regional $\mathrm{CB}$ damage on specific aspects of cognition, and to determine the $\mathrm{CB}$ contribution to these functions. This information will improve the ability to predict which $\mathrm{CB}$ patients may be diagnosed with the CCAS, and provide targets for remediation of cognitive deficits in $\mathrm{CB}$ populations.

\section{Introducing Cognition into Cerebellar Rehabilitation: Facts and Hopes (M. Adamaszek, M. Masciullo, and M. Molinari)}

CB damage has been associated with several movement disorders including incoordination, reduced manual dexterity, postural instability, and gait disturbances [131-133]. Patients with $\mathrm{CB}$ lesions obviously should participate in conventional rehabilitation interventions, including speech therapy, coordination exercises, therapy for balance, mobilization, motor reeducation, as well as various occupational therapy activities [134].

Historically, in line with the classical view of the CB as a motor center, the main focus of rehabilitation approaches has been on motor aspects, mainly ataxia and dysmetria [135, 136], although there is limited evidence about their effectiveness [137-140].

Recovery following CB damage is, indeed, slow and often incomplete [141], and it has been suggested that individuals with focal lesions have better recovery than those with diffuse lesions [134, 142]. Moreover, as the result of the modulatory CB role upon remote structures (such as the cerebral cortex), CB injury may give rise to a constellation of behavioral, affective, and cognitive symptoms (CCAS), that may further impact function and the rehabilitation process.

Indeed, regarding function recovery, Ilg and colleagues proposed that, after CB damage, walking is no longer automatic, and as every step would be a conscious movement, pathways through the ("cognitive") cerebro-CB would be engaged [133]. Therefore, if there is damage throughout the CB, individuals would not only experience the difficulties 
resulting from the damaged ("motor") spino-CB but would also have difficulties compensating due to the cerebro-CB damage.

The key $\mathrm{CB}$ role in motor learning and adaptation following extra-CB pathology $[135,143]$ may limit functional recovery in people with $\mathrm{CB}$ dysfunction. Appreciating the central role of the $\mathrm{CB}$ in motor learning and learning through error informs our understanding of why individuals with $\mathrm{CB}$ lesions take longer to relearn the skills of walking and require more repetition than individuals with other central nervous system lesions. In this context, it may also be necessary to use compensatory aids and strategies for those with more severe $\mathrm{CB}$ damage.

As previously mentioned, CB lesions may cause loss of activity within the cerebral cortex due to the large interconnections between these structures. In this context, there has been significant advances in the CB neuroscience of cognitive functions, mainly provided by conceded clinical and particularly neuroimaging protocols. High-resolution structural and functional MRI and recent developments in fiber-tracking techniques such as DTI and DSI yielded deeper anatomical insight to the CB and its connections to incoming and forwarding signal connections to cerebral areas, among them the prefrontal, parietal, and temporal cortices in accordance with cognitive domains of attention, working memory, and a broad range of executive functions, including cognitive- and affective-behavioral control [21, 144]. Moreover, CB rTMS has started to disentangle the widespread scale of the underlying neurophysiological signal patterns of different $\mathrm{CB}$ network connections to the cerebrum [145]. Finally, yet with less clinical impact, EEG recordings implementing MEG and ERP protocols [146] have been proven to enrich principal research in the cognitive $\mathrm{CB}$. This is in order to delineate the time course and, therefore, the temporal order in which $\mathrm{CB}$ areas are part of the network activities of attention and cognitive- and affective-behavioral control. These technologies of studying CB pathways in healthy individuals and patients seem to be not only of ongoing interest to forward the current scientific development, but mature for application in clinical requests. Indeed, they allow the identification of the causal CB contribution to cognitive impairment and, furthermore, are useful for guiding the indicated neurorehabilitative therapy most appropriate.

Resolution of cerebro-CB diaschisis after CB lesions may also underlie symptom recovery [147, 148]. In humans with CB dysfunction, for example, an increase in the activation of the medial premotor system while moving has been reported, which may feature a compensation for the lack of activation of the lateral premotor areas that receive extensive $\mathrm{CB}$ input [149]. Torriero and colleagues hypothesized that isolated left $\mathrm{CB}$ damage may reduce excitatory drive to the contralateral right dorsolateral prefrontal cortex, resulting in an imbalance in activity between the left and right cortex. Readdressing this imbalance temporarily by inactivating the left dorsolateral prefrontal cortex (rTMS) resulted in improved procedural learning [150]. Considering the emerging demand for neurorehabilitation of cognitive impairment due to $\mathrm{CB}$ disorders at a clinical neuropsychological level, a growing spectrum of increasingly powerful computer-based intervention programs, personal teaching methods (e.g., metacognitive or cognitive-behavioral training) including an individual reward option and the frequent task to engage patients' awareness of afflicted cognitive facilities, and external support by timescheduling devices (e.g., a pager), are feasible recommendations [151]. Proof-of-principle protocols of transcranial stimulation (tDCS, rTMS) are of growing interest, at least for enhancing the clinical neurotherapeutic approaches. These require a strong investigational consideration in clearly described therapeutic protocols regarding some crucial issues, such as the etiology of CB disorder (focal vs. extensive degenerative), the type and site of stimulation, but also the cognitive domain of interest [152]. Similarly, confined physiotherapeutic and occupational therapeutic applications could potentiate the clinical outcome in cognitive disabilities in CB disease, especially if considered in corroborating motor rehabilitation intention. Neuropharmacological aspects of supporting the endeavors of $\mathrm{CB}$-cerebral function restoration as in particular provided along serotonergic and GABAergic receptor profiles might be of interest in outstanding clinical studies. Notwithstanding, an individual but sophisticated combination of clinical and neurophysiological diagnostic protocols, the latter implementing fMRI, rTMS, and/or ERP paradigms to depict morphometric and/or temporal indications of therapeutic-dependent changes in cognitive functioning, is recommended to evaluate the effectiveness of multimodal cognitive interventions in order to advance the quality of outcome measurement [153].

Given the central $\mathrm{CB}$ role in cognition, patients with $\mathrm{CB}$ lesions should be assessed for cognitive deficits in the course of their overall evaluation during rehabilitation. The data obtained from these assessments will be helpful for treatment planning. This may include (i) understanding memory impairments that limit patients' ability to retain elements of the treatment regimen, (ii) determining difficulties with comprehension and abstract reasoning that could interfere with the ability to process treatment information and to function safely upon discharge, and (iii) identifying visual-perceptual-motor deficits that could compromise patients' acquisition and usage of important environmental information and cues (and could further risk safety).

The individuation of specific cognitive profile should be, therefore, mandatory in cognitive rehabilitation of patients with $\mathrm{CB}$ signs. Although CB-induced deficits are typically more subtle in adults, the clinical symptoms clearly resemble those caused by supratentorial lesions [12, 15]. Nevertheless, evidence suggests that the CB-induced cognitive deficits should be treated in a manner different from similar cognitive 
deficits arising from cortical damage [154]. Although systematic studies are clearly warranted, available evidence suggests that CCAS should be treated in a specific way. Approaches where the patients are explicitly made aware of their deficits and are assumed to act as an "external cerebellum" could be considered the most promising in the future [54].

Moreover, a question which requires further research is the elucidation of the patterns of recovery following an acute CB lesion versus a more complex impairment of the $\mathrm{CB}$-cerebral pathways. For the motor $\mathrm{CB}$ syndrome, a stage-by-stage recovery process has been uncovered [155]. Regarding CCAS, we are facing a gap in understanding how recovery evolves. Whether the motor deficits and the cognitive/affective deficits are correlated remains unclear. Further research in embodiment mechanisms is of high interest for understanding the specific functional organization of $\mathrm{CB}$-cerebral networks in coupling motor and nonmotor sequences.

\section{Replication of CCAS (J. D. Schmahmann and $M$. Leggio)}

\section{Introduction}

The emerging field of $\mathrm{CB}$ cognitive neuroscience coalesced with the description of CCAS first in adults [12] and then in children [60]. It underscored the clinical relevance of the new field of the $\mathrm{CB}$ cognitive neuroscience and had immediate implications for the diagnosis and care of patients with neurological and neuropsychiatric disorders. It also demonstrated the clinical relevance of the rediscovery of early suggestions about a CB role outside motor control, the reinterpretation of early anatomical studies, novel anatomical observations of CB incorporation into the distributed neural circuits subserving a wide range of human behaviors, early functional imaging studies showing $\mathrm{CB}$ activation in cognitive tasks, and new theories about CB function [156].

When Manto and Mariën [15] introduced the eponymous designation "Schmahmann syndrome" for the CCAS, they conceptualized it as the third cornerstone of ataxiology, along with the motor and vestibular disorders. Converging data now reveal that the sensorimotor $\mathrm{CB}$ has a primary representation in the anterior lobe bordering on lobule VI and a second representation in lobule VIII; and the cognitive-limbic CB has three representations in the posterior lobe-lobule VI/Crus I, Crus II/VIIB, and lobules IX/X [21, 22, 24]. The high degree of functional topography in these CB cortical areas parallels the connectional specificity in anatomical studies [157] and the intradomain cognitive topography within individual lobules (e.g., different aspects of working memory recruit adjacent regions of lobule VIIB; [158]). It has been proposed that the CCAS represents the clinical manifestation of dysmetria of thought, the result of disruption of the UCT applied to the loops of information processing that subserve cognition and emotion in addition to sensorimotor control [3,5]. It therefore has broad ramifications for understanding the mechanisms of cognition because it necessitates the incorporation of the $\mathrm{CB}$ and other subcortical nodes into the neural circuits relevant to human behavior $[157,159,160]$.

Here, we review the replication of the CCAS over the past two decades in adults and children with inherited and acquired CB diseases. For comprehensive reviews, see $[2,3,10,11,13$, 54, 93, 156, 157, 161-167].

\section{Cerebellar Stroke}

Lesion-deficit studies in patients with focal injury provide pivotal insights into structure-function correlations. When stroke involves the superior $\mathrm{CB}$ artery (SC-Art) which irrigates the anterior lobe and adjacent sectors of lobule VI, the clinical features conform to the $\mathrm{CB}$ motor syndrome of gait ataxia, ipsilateral limb dysmetria, and dysarthria [48, 51, 168-173]. VLSM demonstrates somatotopic representation of the limbs, trunk, gait, and speech [45]. The SC-Art territory is not exclusively confined to the anterior lobe, and visualspatial deficits have also been described following SC-Art stroke [174].

Functional topography in the CCAS was evident from the outset, occurring in patients with posterior lobe stroke [12]. In 39 subsequent CB stroke patients [28], 26 (66.6\%) had the CB motor syndrome, but 13 (33\%) were motorically normal. Motor findings were in patients with anterior lobe lesions, whereas those with stroke in lobules VII-X had no ataxia. A VLSM study [17] confirmed and extended these observations with a double dissociation: stroke in the anterior lobe produced the $\mathrm{CB}$ motor syndrome but not the CCAS, whereas stroke in the posterior lobe produced the CCAS but not the motor syndrome. These observations are consistent with the CB functional topography in healthy controls with task-based $[21,43,175]$ and resting-state fMRI [22, 24].

Review of the CB stroke literature reveals that all CCAS elements may occur following focal CB lesions. Some of these reports are highlighted here.

- Posterior inferior CB artery (PICA) territory strokes in the right $\mathrm{CB}$ hemisphere degraded error detection, practicerelated learning of a verb-for-noun generation task [176] and produced agrammatic speech [177].

- Eighteen young adults with isolated CB stroke were impaired on tasks of working memory, motor speed, and integration of visual, spatial, and motor skills [178].

- Fifteen patients with isolated CB infarcts (PICA, 10; SCArt, 4; AICA 1) had executive dysfunction with impaired phonemic and alternating category fluency, naming with and without interference, and paced auditory serial addition task, visual-spatial deficits on the WAIS-R Block 
Design test, and personality changes including disinhibition [179].

- Six PICA stroke patients had deficits in visual-spatial working memory, attention and verbal episodic memory, and elevated scores on psychopathology scales [180].

- Thirty-seven patients with isolated CB infarcts had elevated scores on a frontal systems impairment index, delayed recall of verbal or visual information, anomic aphasia, limb kinetic apraxia, and acquired dyslexia [181]. Another 43 with isolated CB or brainstem infarcts were impaired on tests of apathy, disinhibition, executive function, and emotional intelligence [182].

- Twenty-two (88\%) of 25 Russian patients with isolated CB infarcts showed impaired attention, cognitive control, and mental flexibility [183]. Six (24\%) with right PICA strokes had linguistic difficulties - naming, irregularity of speech, agrammatism, and aprosodia, and memory impairment with loss of previously acquired habits, facial agnosia, amusia, and temporal disorientation.

- Twenty-six patients with isolated CB infarcts demonstrated impaired working memory and visuospatial and visuomotor abilities, with greater deficits following right-sided lesions [184].

- In 19 patients with isolated CB lesions and 6 with idiopathic $\mathrm{CB}$ ataxia, verbal fluency was impaired in a modality-specific manner, phonemic fluency more impaired than semantic fluency [185]. Both left- and rightsided damage caused reduced verbal fluency, with a slightly greater right-sided predominance. Patients with $\mathrm{CB}$ degeneration were subsequently shown to produce fewer words than healthy controls, even when controlling for slowed articulation, with a trend for patients to produce fewer responses during the phonemic compared to the semantic condition [186].

- In a VLSM study of 21 adults with remote CB stroke (46.7 \pm 17.0 months), impaired phonemic fluency correlated with lesions in the cortex and white matter of right Crus II, the deep nuclei, and lobules IX and X [187].

- The right $\mathrm{CB}$ was also implicated in decreased phonemic fluency in a study of chronic CB hemisphere lesions from stroke or tumor resection ([188], $n=22 ;$ [189], $n=32$ ).

- Executive function, mental flexibility, focused attention, and real-life errand tasks were impaired in patients with CB injury [190] $(n=11)$, together with deficient reverse digit span [191] $(n=15)$, and impaired verbal working memory [192] $(n=9)$. Both components of verbal shortterm memory are affected by CB lesions (the rehearsal system [193] and the phonological short-term store [194]), suggesting that the CB serves as an interface between the phonological short-term store and articulatory rehearsal, comparing the output of subvocal articulation with the contents of the phonological store [41].
- The essential elements of CCAS - language, executive function, and visuospatial abilities, were confirmed in a retrospective study of 156 patients, 78 with isolated $\mathrm{CB}$ lesions and 78 with $\mathrm{CB}$ atrophy [16]. Cognitive deficits were most marked in patients with lesions in the PICA territory and the deep CB nuclei. Further, sequencing deficits were the most marked cognitive impairment in all patients, with the exception of those in whom the $\mathrm{CB}$ nuclei were spared.

Case reports of $\mathrm{CB}$ stroke provide granular detail about the personal impact of the CCAS. These include emotional dyscontrol and aggression [195]; impaired language processing with decreased verbal fluency and semantic deficits [196-198]; transcortical sensory aphasia with impaired reading and writing [199]; spatial dysgraphia [200]; impaired verbal learning and memory [195, 201]; executive dysfunction including difficulty following complex conversations, making decisions, planning, abstract reasoning, set-shifting, and perseveration [196-199, 201]; loss of emotions [201]; psychomotor agitation, spatial-temporal confusion, alteration of personality with dysphoria, disinhibition, affective indifference to family, and panic disorder [197]; disinhibition with disorders of judgment and reasoning [202]; and cognitive slowing affecting visuospatial analysis [199, 202, 203].

\section{CCAS in the Hereditary Ataxias}

Cognition is involved to varying degrees in the genetically defined SCAs [204]. These deficits conform to the pattern of the CCAS - deficits in executive function, linguistic processing, spatial cognition, verbal and visual memory, and changes in affect. Even SCA6, the purest CB form of the SCAs, has problems with executive function, and in the study of Hoche and colleagues [13], there were no group differences in cognition between patients with complex cerebro-CB disease versus isolated CB pathology except for a test of similarities in which complex patients were more impaired. Orsi and colleagues [205] observed memory, language, visuospatial, attentional, executive, and mood changes consistent with the CCAS in patients with SCA1, 2, 6, and 8, with no significant differences between subgroups. Cognitive changes deepen as the disease evolves, as described in SCA3 [206]. True amnestic dementia sets in late in the illness in some SCAs, likely reflecting neuropathology involving medial temporal lobe structures, because long-term recall is usually relatively spared in the CCAS $[12,13,60]$, even though access to stored events and facts through executive control of recall is impaired. Lindsay and Storey [207] point out that disorders like SCA17 with disseminated neuropathology may produce widespread cognitive impairment including dementia.

CCAS is reported in hereditary ataxias in which neuropathology is thought to be restricted to the $\mathrm{CB}$ and its 
connections. Ataxia telangiectasia, a childhood-onset disorder from mutations in the ATM gene causing progressive CB degeneration [208], is associated with cognitive impairments that become more appreciable as the disease evolves [209, 210]. Autosomal recessive $\mathrm{CB}$ ataxia type 1 , also confined to $\mathrm{CB}$, has findings consistent with the CCAS [211]. And Friedreich's ataxia, a predominantly afferent ataxia with involvement also of the deep CB nuclei, involves slowing of cognition [212] and impairments in verbal fluency, working memory, and social cognition [213].

Neuroimaging in the hereditary ataxias reveals that atrophy in different $\mathrm{CB}$ subregions may account for the specificity of cognitive symptoms. In patients with SCA2, atrophy in the cognitive $\mathrm{CB}$ in the posterior lobe (lobules VI, Crus I, Crus II, VIIB, and IX) correlated with impaired visuospatial, verbal memory, and executive function, whereas atrophy in the motor CB (lobule V in the anterior lobe; lobules VIIIA and VIIIB of the posterior lobe) correlated with motor deficits and impaired motor planning [214]. CB atrophy was also associated with altered diffusivity of the middle and superior $\mathrm{CB}$ peduncles, the main cerebro-CB afferent and efferent white matter tracts, respectively, indicating that cerebro-CB dysregulation may account for the CCAS in SCA2 [215]. Network-based statistics reveals that altered internodal connectivity between the $\mathrm{CB}$ posterior lobe and the cerebral cortex correlated with assessments of cognition and emotion, consistent with the view that $\mathrm{CB}$ dysfunction in SCA2 affects cerebral regions at a distance and that the clinical symptoms may be related to connectivity changes in both the cerebral and CB nodes of motor and nonmotor cerebro-CB circuits [104]. These findings are consistent with the observations that there are distinct and topographically precise $\mathrm{CB}$ contributions to cerebral intrinsic connectivity networks $[24,25,39]$ and that rTMS applied to distinct $\mathrm{CB}$ regions can selectively modulate network functional connectivity in healthy individuals $[145,216]$. Further, dysfunctional connectivity between the $\mathrm{CB}$ and the dorsolateral prefrontal cortex is associated with negative symptom severity in schizophrenia, and improvement of the connectivity ameliorates the severity of the negative symptoms [217].

\section{Language in the CCAS}

Language difficulties in the CCAS included dysprosodia, agrammatism, anomia, impaired syntax, and deficits in verbal fluency and telegraphic speech $[12,177]$, while children with CCAS experienced expressive language deficits, word finding difficulties, and mutism in those with vermal damage [60]. Subsequent studies showed CB contributions to speech and language perception, grammar, motor speech planning, syntax processing, and the dynamics of language production including writing and reading skill $[93,200,218]$. CB patients are impaired on a word stem completion task [186] and on metalinguistics, the higher-level language function essential for social interaction, including the ability to engage with and respond to the contextual and situational demands of normal discourse [219, 220].

\section{Attention in the CCAS}

Behavioral and neuroimaging studies demonstrate a $\mathrm{CB}$ role in attention, which is impaired in patients with the CCAS [14]. This topic has remained controversial [221]. In a study of SCA2 patients [222], Go/NoGo and divided and sustained attention were impaired. These tasks depend on multisensory integration, sequencing, prediction of events, and inhibition of inappropriate responses, all of which are affected by CB damage. Further, divided and sustained attention correlated with lobules VIIB/VIIIA which have been proposed to be part of the dorsal attention network [104, 223], and selective attention correlated with vermis lobule VI. These findings provide support for the involvement of specific $\mathrm{CB}$ regions in the attention impairments seen in the CCAS and for the inclusion of the $\mathrm{CB}$ within the dorsal attention network.

\section{Cognitive Sequencing in the CCAS}

Sequence detection has been proposed as the operational mode of the CB in different domains [112, 164, 224-226]. Sequencing abilities are impaired in CB patients [16], for both sensory-motor [227-233] and cognitive domains [224]. Further, left-sided lesions impair the ability to detect and correctly reproduce sequences based on pictorial material, whereas right-sided lesions degrade sequencing ability when verbal elaboration is required [112].

\section{CCAS in Children}

The CCAS occurs in children with CB stroke. Five boys (age 3-14) had mood disturbances, outbursts of laughter and/or crying, and alternating agitation or prostration. Cognitive deficits included mutism followed by anomia and impaired comprehension, planning, visual-spatial organization, and attention. The cognitive difficulties improved slowly and incompletely and were more disabling than the motor symptoms [234].

Central nervous system tumors disproportionately affect posterior fossa structures in childhood. Levisohn and colleagues [60] first addressed the question of cognitive change in children who underwent $\mathrm{CB}$ tumor resection without confounding brain radiation and use of methotrexate. In 19 children (age 3-14), they noted problems with attention and executive impairments in sequencing, planning, and establishing and maintaining set. Expressive language was characterized by reluctance to engage in conversation, long response latencies, brief responses, lack of elaboration, and difficulties with 
language initiation, word finding, and confrontation naming. Many had problems solving strategies, visual-spatial deficits, impaired verbal recall, and failure to organize verbal or visual-spatial material for encoding that impacted retrieval. Impaired regulation of affect following vermal damage manifested as irritability, impulsivity, disinhibition, and lability, with poor attentional and behavioral modulation. Subsequent studies revealed impaired executive functions with deficient planning, sequencing, mental flexibility and hypothesis generation and testing, also involving visual-spatial function, expressive language, and verbal memory [235-241]. Similar phenomena were observed by Riva and Giorgi [59] $(n=26)$, who reported impaired verbal intelligence, auditory sequential memory, and language following right-sided tumors, and deficient nonverbal tasks including spatial and visual sequential memory and impaired prosody after left-sided tumors. Similar findings have been observed by others [184, 242, 243]. Behavioral changes can be marked and include disinhibition, impulsivity and irritability [244], dysphoria and inattention [237], anxiety, aggression [245], and stereotypes and aberrant interpersonal relations meeting criteria for the diagnosis of ASD [59].

Posterior fossa tumor resection in children can be complicated by the development of CB mutism [60, 246-253]. The consensus understanding of postoperative pediatric $\mathrm{CB}$ mutism syndrome [254] is that after a latent period of 1 to 2 days following $\mathrm{CB}$ or 4 th ventricle tumor resection, children develop "mutism / reduced speech and emotional lability... Additional common features including hypotonia and oropharyngeal dysfunction / dysphagia. It may frequently be accompanied by the cerebellar motor syndrome, the cerebellar cognitive affective syndrome, and brainstem dysfunction including long tract signs and cranial neuropathies." CCAS is thus the behavioral syndrome accompanying mutism, and it may persist after the transient period of mutism has resolved. Behavioral changes include regressive personality, apathy, and poverty of spontaneous movement. Emotional lability can be marked, with rapid cycling of emotional expression between irritability, inconsolable crying and agitation, to giggling and easy distractibility. CB mutism also occurs following stroke or hemorrhage in children $[234,255]$ and adults [256], and diminished verbal fluency approaching mutism was described in the original study following postinfectious cerebellitis [12].

\section{Developmental CCAS}

Disruptions and gene disorders causing $\mathrm{CB}$ malformations result in a developmental form of CCAS. Children with $\mathrm{CB}$ hemorrhages in utero or early postnatal life have problems with expressive and receptive language and behavioral and social deficits that meet criteria for ASD in more than $40 \%$ $[257,258]$. These observations of long-term sequela following
CB hemorrhage in children have been confirmed by others [259]. Developmental CCAS was also observed in three brothers with hindbrain malformation in Joubert syndrome, a mutation in the TMEM67 gene [260]. The siblings were developmentally delayed, demonstrating disproportionate cognitive weaknesses in selected aspects of executive function, language processing, and the visuospatial domain, as well as a pronounced neuropsychiatric constellation. The long-term consequences of $\mathrm{CB}$ malformations on cognitive development may reflect a deficit in sustaining projections between $\mathrm{CB}$ and cerebral cortical and subcortical sites, functioning through trophic mechanisms required for the development and pruning of connections $[2,157,258,261,262]$.

\section{Neuropsychiatry of the Cerebellum; the Affective Component of the CCAS}

Emotional dysregulation can be prominent in CCAS [12, 60] and can be marked in children following tumor resection, as above. Patients with midline lesions demonstrate socialemotional aberrant behaviors [3, 12, 58, 60, 263], and social cognition is impaired in $\mathrm{CB}$ patients assessed using the "Reading the Mind in the Eyes" test [109]. CB lesions also affect encoding and processing of external negative stimuli [222] and conscious self-monitoring of negative emotion [264].

Opsoclonus myoclonus syndrome is a postinfectious or paraneoplastic immune-mediated phenomenon with a psychiatric constellation of mood changes, irritability, lability, aggression, and night terrors $[265,266]$. Dysphoric mood, disinhibition and poor affect regulation, disruptive behaviors, and temper tantrums occur together with cognitive and language impairment [14, 266, 267].

Depression had a prevalence of $26 \%$ in the natural history study of 300 patients with SCAs 1, 2, 3, and 6, and suicidal ideation was present in $65 \%$ of the SCA3 patients [268]. CCAS is under active investigation in other psychiatric disorders including schizophrenia and ASD [3, 269-274]. CB lesions may dysregulate mood and personality and trigger psychotic thinking and behaviors that meet criteria for diagnoses of attention deficit hyperactivity disorder, obsessivecompulsive disorder, depression, bipolar disorder, ASD, atypical psychosis, anxiety, and panic disorder. These neuropsychiatric presentations have been conceptualized as emotional overshoot (hypermetria) or undershoot (hypometria) within five neuropsychiatric domains - attentional control, emotional control, social skill set, psychosis spectrum disorders, and ASD [14].

Single case studies provide the clinical relevance of these new approaches $[14,275]$. This is exemplified by the recent report of a patient with rupture of a $\mathrm{CB}$ arteriovenous malformation who developed mania and personality and mood changes consistent with a borderline personality and bipolar 
I disorder [261]. The CB damage involved left lobules VI, VIIA-Crus I, and IX, and the posterior vermis. Altered functional connectivity was detected in prefrontal-striatal-thalamic circuits implicated in bipolar subjects during the manic state [276].

The CB role in ASD is an area of active investigation. Recent resting-state fMRI studies in ASD reveal altered functional connectivity between the dentate nucleus and the cerebral cortex [119] and decreased volume in right Crus II that correlates with the degree of autistic traits. Right Crus II is interconnected with contralateral frontal and temporal areas related to social cognition, and altered functional connectivity has been reported between the smaller Crus II and these cerebral areas [277]. In the Tsc1 (tuberous sclerosis) mouse model of ASD, neuromodulation of right Crus I (hemispheric extension of lobule VIIA) rescued social deficits, consistent with the suggestion that the dysfunction of cerebro-CB circuits underlies selected aspects of disrupted behavior in ASD [278]. It therefore appears likely that dysfunction reported within neural circuits engaged in social cognition in ASD is related, at least in part, to impaired interactions between focal $\mathrm{CB}$ regions and critical cerebral cortical nodes of the social brain.

\section{CCAS/Schmahmann Syndrome Scale}

The diagnosis of the CCAS at the bedside or in the office has been a challenge, requiring comprehensive neuropsychological testing. This need was addressed by Hoche and colleagues [13], who studied 77 patients with CB disease, and 39 more in a validation cohort, to develop a brief battery of tests to identify the CCAS. This study reaffirmed the core executive, visual-spatial, linguistic, and affective features of the CCAS. It then used the data to derive the CCAS/Schmahmann Scale, a 10 -min battery of cross-domain assessments to diagnose CCAS in patients with $\mathrm{CB}$ lesions with certainty. The new scale makes it possible to assess cognition and affect in $\mathrm{CB}$ patients, which is proving to be useful for both clinical and research purposes.

\section{Conclusion}

Each aspect of the CCAS has been replicated in studies over the 20 years since its description. Ongoing studies of its executive, linguistic, visual-spatial, and affective components confirm each of these domains and provide new details about how they manifest in different disease states and at different ages. The introduction of the CCAS Scale and the adaptation of the tools of contemporary cognitive neuroscience to study the $\mathrm{CB}$ may add greater depth and complexity to the understanding of the $\mathrm{CB}$ role in cognition and emotion. They also hold promise for new approaches to the treatment of neurobehavioral/ neuropsychiatric manifestations of CB disorders.

\section{Discussion: Consensus on CCAS and Future Directions (G.P.D. Argyropoulos, K. van Dun, and R.B. Ivry)}

This paper gathered contributions from experts in the field of CB neurocognition, attempting to promote awareness of CCAS as a clinical entity and stimulate further research. The authors substantiated the concept of CCAS with recent evidence from different angles and examined current insight into rehabilitation. Several points of convergence were identified, with respect to both the interpretation of the findings in the literature and the outstanding questions for future research.

\section{Towards Voxel-Based Approaches}

CCAS provides a clinical entity that lends support to a $\mathrm{CB}$ role in cognition and affect. Nevertheless, the majority of $\mathrm{CB}$ lesion-symptom mapping studies on nonmotor function have relied on single cases or patient cohorts divided according to crude grouping criteria. The introduction of VLSM in focal $\mathrm{CB}$ lesions, and VBM in degenerative $\mathrm{CB}$ disease, affords us the level of spatial precision ("Cerebellar Functional Topography in CCAS: Updates and Challenges," "Cerebellar Neurocognition: Relevance to CCAS," and "Replication of CCAS" sections) required to address the fact that cortico-CB functional networks do not abide by lobular boundaries. Such precision is also fundamental for symptom prediction and intervention planning ("Cerebellar Neurocognition: Relevance to CCAS" and "Introducing Cognition into Cerebellar Rehabilitation: Facts and Hopes" sections). Importantly, though, these methods require relatively large patient cohorts, and research would benefit from multi-center collaborations ("Cerebellar Functional Topography in CCAS: Updates and Challenges" section).

\section{Research on Social Cognition and Affect}

The lack of sophisticated lesion-symptom mapping methods is particularly evident in the affective component of CCAS. This has been assessed in a less systematic fashion, with many studies employing clinical psychiatric assessment, with psychopathological diagnoses based on DSM. Moreover, there is no clear spatial segregation of neo-CB regions in terms of functional connectivity with limbic versus association cortices. Functional imaging of affective processing supports a $\mathrm{CB}$ role, but this is not confined to what is considered the limbic $\mathrm{CB}$, i.e. the posterior vermis ("Cerebellar Functional Topography in CCAS: Updates and Challenges" section). Work on $\mathrm{CB}$ contributions to social cognition can inform further research on the $\mathrm{CB}$ and affect, although, similarly, imaging and stimulation studies on the mechanisms underlying impaired social action sequencing are currently lacking 
("Cerebellar Neurocognition: Relevance to CCAS" and "Replication of CCAS” sections).

\section{Noninvasive Cerebellar Stimulation}

Noninvasive stimulation, in particular (primarily tDCS and rTMS), is promising with respect to investigating cortico-CB connectivity and identifying causal relationships between $\mathrm{CB}$ function and behavior ("Cerebellar Neurocognition: Relevance to CCAS" section; but see [279] for concerns with replicability). Especially when combined with the newest imaging techniques, a better understanding can be obtained of the mechanisms underlying the symptoms, which can lead to a very specific goal-directed therapeutic approach ("Introducing Cognition into Cerebellar Rehabilitation: Facts and Hopes" section; see also [19]).

\section{Cerebellar Versus Cortical Cognitive Deficits}

The identification of CCAS also highlights the importance of assessing patients with $\mathrm{CB}$ lesions in cognitive function, both at the acute stage and over the course of their rehabilitation ("Introducing Cognition into Cerebellar Rehabilitation: Facts and Hopes" and "Replication of CCAS" sections). Consistent with the modulatory $\mathrm{CB}$ role in nonmotor function, the cognitive deficits that may follow neo-CB lesions often reflect those observed after prefrontal damage, albeit in a milder fashion ("Cerebellar Functional Topography in CCAS: Updates and Challenges" and "Introducing Cognition into Cerebellar Rehabilitation: Facts and Hopes" sections). Further research is required to investigate whether CBinduced cognitive impairment should be treated in a manner distinct from deficits following cortical damage, and specific techniques may be required for rehabilitation ("Introducing Cognition into Cerebellar Rehabilitation: Facts and Hopes" section; see also [154]).

\section{From Functional Domains to Computations}

The development of rehabilitation approaches would benefit substantially from identifying the particular CB computations across functional domains ("Introducing Cognition into Cerebellar Rehabilitation: Facts and Hopes" section). The question of relevance no longer pertains to the presence of a CB role in cognition and affect, but to the computation by which this is accomplished [2]. The term "dysmetria of thought" is, at present, descriptive, providing a broad characterization rather than specifying underlying mechanistic impairments. Various hypotheses have been put forth that might form the basis of the UCT, such as error-based learning, error monitoring, forward control, prediction, timing, or sequencing ("Cerebellar Neurocognition: Relevance to CCAS," "Introducing
Cognition into Cerebellar Rehabilitation: Facts and Hopes," and "Replication of CCAS" sections). The variability in the cognitive deficits observed may be explained by the extent to which this $\mathrm{CB}$ computation is required in particular tasks [280]. Alternatively, the CB role in cognition and affect may be modulatory, helping coordinate processing within extra-CB structures. Identifying core computations will require a move beyond standard neuropsychological assessment, toward finer-grained behavioral paradigms.

\section{Beyond the "Motor Versus Cognitive" Dichotomy}

Indeed, it may be argued that the distinctions between functional domains may obfuscate the computations performed. While distinct relationships have been identified between the domain of impairment and the localization of $\mathrm{CB}$ damage ("Cerebellar Neurocognition: Relevance to CCAS" and "Replication of CCAS" sections), we may still need to revise our methods for distinguishing between "motor" and "cognitive" function, open to the idea that $\mathrm{CB}$ function may require considering interfaces between higher-level function and motor-like operations ("Cerebellar Functional Topography in CCAS: Updates and Challenges" section).

\section{Broader Networks}

Such network integration is of importance in considering symptom recovery and rehabilitation. Given the welldocumented cerebro-CB structural and functional connectivity ("Cerebellar Functional Topography in CCAS: Updates and Challenges," "Cerebellar Neurocognition: Relevance to CCAS," and "Replication of CCAS" sections), the presence of diaschisis and the time course of its resolution need to be factored in for the prediction of symptom recovery and the development of rehabilitatory interventions ("Introducing Cognition into Cerebellar Rehabilitation: Facts and Hopes" section). Similarly, understanding the time course of different symptom clusters could offer clues concerning their direct (CB) or indirect origins (off-target effects). Indeed, very little is known on the way in which the behavioral consequences of CB damage are modulated by extra-CB pathology. This network-based approach should be extended beyond cortico$\mathrm{CB}$ circuits, to incorporate findings on the structural and functional connectivity of the $\mathrm{CB}$ with the $\mathrm{BG}$ and the medial temporal lobe ("Cerebellar Functional Topography in CCAS: Updates and Challenges" section). Longitudinal follow-up studies of CB patients, investigating behavioral improvement linked to the results obtained with structural and functional imaging techniques, might provide further insight into the $\mathrm{CB}$ role and the compensatory mechanisms after deprivation of $\mathrm{CB}$-cerebral communication. 


\section{Conclusion}

CCAS reflects a constellation of CB-induced sequelae in executive function, visuospatial cognition, language, and emotion/affect. As a clinical entity, it supports a CB role in cognition and affect and provides ideal grounds for the investigation of CB contributions in nonmotor functions. Enhanced symptom prediction, intervention planning, and rehabilitation will benefit from (i) patient studies employing finer-grained behavioral paradigms that could identify the CB processes involved in cognition and affect, (ii) sophisticated lesionsymptom mapping methods to highlight intra- and crosslobular regions in relation to particular symptoms, and (iii) research on the indirect effects of focal $\mathrm{CB}$ lesions on behavior by off-target effects and broader network dysfunction.

Funding Information Richard B. Ivry was supported by a grant from the National Institute of Health (NS105839). Maria Leggio was funded by the Italian Ministry of Instruction, University and Research (MIUR) (Grant Number RM11715C7E67E525). Marco Molinari was partially supported by the Italian Ministry of Health (Ricerca Corrente) and partially by Ricerca Finalizzata of the Italian Ministry of Health (RF-201102348213). Catherine J. Stoodley was supported by the National Institutes of Health R15MH106957 and R21DC014087. Jeremy D. Schmahmann is supported in part by the NIH-NINDS, the National Ataxia Foundation, the Ataxia Telangiectasia Children's Project, and the MINDlink Foundation. Frank Van Overwalle was partly funded by a Strategic Research Program (SRP15) awarded by the Vrije Universiteit Brussel, Belgium.

\section{Compliance with Ethical Standards}

Conflict of Interest Dr. Schmahmann discloses that he consults for Bayer, Biogen, Biohaven, and Cadent Pharmaceuticals; is on the scientific advisory boards of the National Ataxia Foundation, the Society for Research on the Cerebellum and Ataxias, and the executive of the American Neuropsychiatric Association; receives royalties from Oxford University Press, Elsevier, and MacKeith Press; and holds the license with the General Hospital Corporation to the Brief Ataxia Rating Scale, the Brief Ataxia Scale revised, the Cerebellar Cognitive Affective / Schmahmann Syndrome scale, the Cerebellar Neuropsychiatric Rating Scale, and the Patient Reported Outcome Measure for Ataxia (PROMAtaxia). None of these disclosures represents a conflict of interest that may be perceived as biasing the content of this contribution. The other authors declare no competing financial interests.

Open Access This article is distributed under the terms of the Creative Commons Attribution 4.0 International License (http:// creativecommons.org/licenses/by/4.0/), which permits unrestricted use, distribution, and reproduction in any medium, provided you give appropriate credit to the original author(s) and the source, provide a link to the Creative Commons license, and indicate if changes were made.

\section{References}

1. Schmahmann JD. Rediscovery of an early concept. Int Rev Neurobiol. 1997;41:3-27.
2. Koziol LF, Budding D, Andreasen N, D'Arrigo S, Bulgheroni S, Imamizu $\mathrm{H}$, et al. Consensus paper: the cerebellum's role in movement and cognition. Cerebellum. 2014;13:151-77.

3. Schmahmann JD. An emerging concept. The cerebellar contribution to higher function. Arch Neurol. 1991;48:1178-87.

4. Schmahmann JD. From movement to thought: anatomic substrates of the cerebellar contribution to cognitive processing. Hum Brain Mapp. 1996;4:174-98.

5. Schmahmann JD. The role of the cerebellum in affect and psychosis. J Neurolinguistics. 2000;13:189-214.

6. Ito M. The cerebellum and neural control. New York: Raven Press; 1984.

7. Manto M, Bower JM, Conforto AB, Delgado-García JM, da Guarda SNF, Gerwig M, et al. Consensus paper: roles of the cerebellum in motor control - the diversity of ideas on cerebellar involvement in movement. Cerebellum. 2012;11:457-87.

8. Schmahmann J, Pandya DN. Anatomic organization of the basilar pontine projections from prefrontal cortices in rhesus monkey. $\mathrm{J}$ Neurosci. 1997; 17:438-58.

9. Middleton FA, Strick PL. Cerebellar output channels. Int Rev Neurobiol. 1997;41:61-82.

10. Bodranghien F, Bastian A, Casali C, Hallett M, Louis ED, Manto $\mathrm{M}$, et al. Consensus paper: revisiting the symptoms and signs of cerebellar syndrome. Cerebellum. 2016;15:369-91.

11. Schmahmann JD. Dysmetria of thought: clinical consequences of cerebellar dysfunction on cognition and affect. Trends Cogn Sci. 1998;2:362-71.

12. Schmahmann JD, Sherman JC. The cerebellar cognitive affective syndrome. Brain. 1998;121:561-79.

13. Hoche F, Guell X, Vangel MG, Sherman JC, Schmahmann JD. The cerebellar cognitive affective/Schmahmann syndrome scale. Brain. 2018;141:248-70.

14. Schmahmann JD, Weilburg JB, Sherman JC. The neuropsychiatry of the cerebellum-insights from the clinic. Cerebellum. 2007;6: 254-67.

15. Manto M, Mariën P. Schmahmann's syndrome - identification of the third cornerstone of clinical ataxiology. Cerebellum \& Ataxias. 2015;2:2.

16. Tedesco AM, Chiricozzi FR, Clausi S, Lupo M, Molinari M, Leggio MG. The cerebellar cognitive profile. Brain. 2011;134: 3669-83.

17. Stoodley CJ, MacMore JP, Makris N, Sherman JC, Schmahmann JD. Location of lesion determines motor vs. cognitive consequences in patients with cerebellar stroke. NeuroImage Clin. 2016;12:765-75.

18. Kirschen MP, Davis-Ratner MS, Milner MW, Chen SHA, Schraedley-Desmond P, Fisher PG, et al. Verbal memory impairments in children after cerebellar tumor resection. Behav Neurol. 2008;20:39-53.

19. Grimaldi G, Argyropoulos GP, Boehringer A, Celnik P, Edwards MJ, Ferrucci R, et al. Non-invasive cerebellar stimulation - a consensus paper. Cerebellum. 2014;13:121-38.

20. Keren-Happuch E, Chen SHA, Ho MHR, Desmond JE. A metaanalysis of cerebellar contributions to higher cognition from PET and fMRI studies. Hum Brain Mapp. 2014;35:593-615.

21. Stoodley CJ, Schmahmann JD. Functional topography in the human cerebellum: a meta-analysis of neuroimaging studies. Neuroimage. 2009;44:489-501.

22. Guell X, Gabrieli JDE, Schmahmann JD. Triple representation of language, working memory, social and emotion processing in the cerebellum: convergent evidence from task and seed-based resting-state fMRI analyses in a single large cohort. Neuroimage. 2018;172:437-49.

23. Krienen FM, Buckner RL. Segregated fronto-cerebellar circuits revealed by intrinsic functional connectivity. Cereb Cortex. 2009;19:2485-97. 
24. Buckner RL, Krienen FM, Castellanos A, Diaz JC, Yeo BTT. The organization of the human cerebellum estimated by intrinsic functional connectivity. J Neurophysiol. 2011;106:2322-45.

25. O'Reilly JX, Beckmann CF, Tomassini V, Ramnani N, JohansenBerg H. Distinct and overlapping functional zones in the cerebellum defined by resting state functional connectivity. Cereb Cortex. 2010;20:953-65.

26. Strick PL, Dum RP, Fiez JA. Cerebellum and nonmotor function. Annu Rev Neurosci. 2009;32:413-34.

27. Blatt GJ, Oblak AL, Schmahmann JD. Cerebellar connections with limbic circuits: anatomy and functional implications. In: Manto M, Schmahmann JD, Rossi F, Gruol DL, Koibuchi N, editors. Handbook of the cerebellum and cerebellar disorders. Dordrecht: Springer; 2013. p. 479-96.

28. Schmahmann JD, MacMore J, Vangel M. Cerebellar stroke without motor deficit: clinical evidence for motor and non-motor domains within the human cerebellum. Neuroscience. 2009;162: 852-61.

29. Schmahmann JD, Doyon J, Toga AW, Petrides M, Evans A. MRI atlas of the human cerebellum. San Diego (CA): Academic; 2000.

30. Larsell O, Jansen J. The comparative anatomy and histology of the cerebellum. Minneapolis (MN): The University of Minnesota Press; 1967.

31. Adrian ED. Afferent areas in the cerebellum connected with the limbs. Brain. 1943;66:289-315.

32. Snider R, Eldred E. Electro-anatomical studies on cerebrocerebellar connections in the cat. J Comp Neurol. 1951;95:1-16.

33. Snider R, Stowell A. Electro-anatomical studies on a tactile system in the cerebellum of monkey (Macaca mulatta). Anat Rec. $1944 ; 457$

34. Grodd W, Hülsmann E, Ackermann H. Functional MRI localizing in the cerebellum. Neurosurg Clin N Am. 2005;16:77-99.

35. Woolsey CN. Summary of the papers on the cerebellum. Res Publ Res Nerv Ment Dis. 1952;30:334-6.

36. Bolk L. Das cerebellum der saugetiere. Jena: Fischer; 1906.

37. Brodal P. The corticopontine projection in the rhesus monkey. Origin and principles of organization. Brain. 1978;101:251-83.

38. Kelly RM, Strick PL. Cerebellar loops with motor cortex and prefrontal cortex of a nonhuman primate. J Neurosci. 2003;23: 8432-44.

39. Habas C, Kamdar N, Nguyen D, Prater K, Beckmann CF, Menon $\mathrm{V}$, et al. Distinct cerebellar contributions to intrinsic connectivity networks. J Neurosci. 2009;29:8586-94.

40. Nitschke MF, Kleinschmidt A, Wessel K, Frahm J. Somatotopic motor representation in the human anterior cerebellum. A highresolution functional MRI study. Brain. 1996;119:1023-9.

41. Desmond JE, Gabrieli JD, Wagner AD, Ginier BL, Glover GH. Lobular patterns of cerebellar activation in verbal workingmemory and finger-tapping tasks as revealed by functional MRI. J Neurosci. 1997;17:9675-85.

42. Grodd W, Hülsmann E, Lotze M, Wildgruber D, Erb M. Sensorimotor mapping of the human cerebellum: fMRI evidence of somatotopic organization. Hum Brain Mapp. 2001;13:55-73.

43. Stoodley CJ, Valera EM, Schmahmann JD. Functional topography of the cerebellum for motor and cognitive tasks: an fMRI study. Neuroimage. 2012;59:1560-70.

44. Wiestler T, McGonigle DJ, Diedrichsen J. Integration of sensory and motor representations of single fingers in the human cerebellum. J Neurophysiol. 2011;105:3042-53.

45. Schoch B, Dimitrova A, Gizewski ER, Timmann D. Functional localization in the human cerebellum based on voxelwise statistical analysis: a study of 90 patients. Neuroimage. 2006;30:36-51.

46. Konczak J, Pierscianek D, Hirsiger S, Bultmann U, Schoch B, Gizewski ER, et al. Recovery of upper limb function after cerebellar stroke: lesion symptom mapping and arm kinematics. Stroke. 2010;41:2191-200.
47. Maderwald S, Thürling M, Küper M, Theysohn N, Müller O, Beck A, et al. Direct visualization of cerebellar nuclei in patients with focal cerebellar lesions and its application for lesionsymptom mapping. Neuroimage. 2012;63:1421-31.

48. Urban PP, Marx J, Hunsche S, Gawehn J, Vucurevic G, Wicht S, et al. Cerebellar speech representation: lesion topography in dysarthria as derived from cerebellar ischemia and functional magnetic resonance imaging. Arch Neurol. 2003;60:965-72.

49. Schoch B, Konczak J, Dimitrova A, Gizewski E, Wieland R, Timmann D. Impact of surgery and adjuvant therapy on balance function in children and adolescents with cerebellar tumors. Neuropediatrics. 2006;37:350-8.

50. Amarenco P, Chevrie-Muller C, Roullet E, Bousser MG. Paravermal infarct and isolated cerebellar dysarthria. Ann Neurol. 1991;30:211-3.

51. Ackermann H, Vogel M, Petersen D, Poremba M. Speech deficits in ischaemic cerebellar lesions. J Neurol. 1992;239:223-7.

52. Trouillas P, Takayanagi T, Hallett M, Currier RD, Subramony SH, Wessel K, et al. International Cooperative Ataxia Rating Scale for pharmacological assessment of the cerebellar syndrome. J Neurol Sci. 1997;145:205-11.

53. Donchin O, Rabe K, Diedrichsen J, Lally N, Schoch B, Gizewski $\mathrm{ER}$, et al. Cerebellar regions involved in adaptation to force field and visuomotor perturbation. J Neurophysiol. 2012;107:134- 47.

54. Schmahmann JD. The role of the cerebellum in cognition and emotion: personal reflections since 1982 on the dysmetria of thought hypothesis, and its historical evolution from theory to therapy. Neuropsychol Rev. 2010;20:236-60.

55. Babb TL, Mitchell AG, Crandall PH. Fastigiobulbar and dentatothalamic influences on hippocampal cobalt epilepsy in the cat. Electroencephalogr Clin Neurophysiol. 1974;36:141-54.

56. Fusar-Poli P, Placentino A, Carletti F, Landi P, Allen P, Surguladze $\mathrm{S}$, et al. Functional atlas of emotional faces processing: a voxelbased meta-analysis of 105 functional magnetic resonance imaging studies. J Psychiatry Neurosci. 2009;34:418-32.

57. Timmann D, Daum I. Cerebellar contributions to cognitive functions: a progress report after two decades of research. Cerebellum. 2007;6:159-62.

58. Tavano A, Grasso R, Gagliardi C, Triulzi F, Bresolin N, Fabbro F, et al. Disorders of cognitive and affective development in cerebellar malformations. Brain. 2007;130:2646-60.

59. Riva D, Giorgi C. The cerebellum contributes to higher functions during development: evidence from a series of children surgically treated for posterior fossa tumours. Brain. 2000;123:1051-61.

60. Levisohn L, Cronin-Golomb A, Schmahmann JD. Neuropsychological consequences of cerebellar tumour resection in children: cerebellar cognitive affective syndrome in a paediatric population. Brain. 2000;123:1041-50.

61. Kim NY, Lee SC, Shin J-C, Park JE, Kim YW. Voxel-based lesion symptom mapping analysis of depressive mood in patients with isolated cerebellar stroke: a pilot study. NeuroImage Clin. 2017;13:39-45.

62. Aarsen FK, Van Dongen HR, Paquier PF, Van Mourik M, Catsman-Berrevoets CE. Long-term sequelae in children after cerebellar astrocytoma surgery. Neurology. 2004;62:1311-6.

63. Steinlin M, Imfeld S, Zulauf P, Boltshauser E, Lövblad K-O, Ridolfi Lüthy A, et al. Neuropsychological long-term sequelae after posterior fossa tumour resection during childhood. Brain. 2003;126:1998-2008.

64. Bates E, Wilson SM, Saygin AP, Dick F, Sereno MI, Knight RT, et al. Voxel-based lesion-symptom mapping. Nat Neurosci. 2003;6:448-50.

65. Timmann D, Brandauer B, Hermsdörfer J, Ilg W, Konczak J, Gerwig M, et al. Lesion-symptom mapping of the human cerebellum. Cerebellum. 2008;7:602-6. 
66. Stone J, Smith L, Watt K, Barron L, Zeman A. Incoordinated thought and emotion in spinocerebellar ataxia type 8 [3]. J Neurol. 2001;248:229-32.

67. Otchy TM, Wolff SBE, Rhee JY, Pehlevan C, Kawai R, Kempf A, et al. Acute off-target effects of neural circuit manipulations. Nature. 2015;528:358-63.

68. Fremont R, Tewari A, Angueyra C, Khodakhah K. A role for cerebellum in the hereditary dystonia DYT1. Elife. 2017;6: e22775.

69. Bostan AC, Strick PL. The cerebellum and basal ganglia are interconnected. Neuropsychol Rev. 2010;20:261-70.

70. Bostan AC, Dum RP, Strick PL. The basal ganglia communicate with the cerebellum. Proc Natl Acad Sci U S A. 2010;107:8452-6.

71. Hoshi E, Tremblay L, Féger J, Carras PL, Strick PL. The cerebellum communicates with the basal ganglia. Nat Neurosci. 2005;8: 1491-3.

72. Heath RG, Dempesy CW, Fontana CJ, Myers WA. Cerebellar stimulation: effects on septal region, hippocampus, and amygdala of cats and rats. Biol Psychiatry. 1978;13:501-29.

73. Harper JW, Heath RG. Anatomic connections of the fastigial nucleus to the rostral forebrain in the cat. Exp Neurol. 1973;39:285-92.

74. Heath RG, Harper JW. Ascending projections of the cerebellar fastigial nucleus to the hippocampus, amygdala, and other temporal lobe sites: evoked potential and histological studies in monkeys and cats. Exp Neurol. 1974;45:268-87.

75. Yu W, Krook-Magnuson E. Cognitive collaborations: bidirectional functional connectivity between the cerebellum and the hippocampus. Front Syst Neurosci. 2015;9:177.

76. Lisman J, Buzsáki G, Eichenbaum H, Nadel L, Rangananth C, Redish AD. Viewpoints: how the hippocampus contributes to memory, navigation and cognition. Nat Neurosci. 2017;20: $1434-47$.

77. Petrosini L, Leggio MG, Molinari M. The cerebellum in the spatial problem solving: a co-star or a guest star? Prog Neurobiol. 1998;56:191-210.

78. Iglói K, Doeller CF, Paradis A-LL, Benchenane K, Berthoz A, Burgess N, et al. Interaction between hippocampus and cerebellum Crus I in sequence-based but not place-based navigation. Cereb Cortex. 2015;25:4146-54.

79. Desmond JE, Fiez JA. Neuroimaging studies of the cerebellum: language, learning and memory. Trends Cogn Sci. 1998;2:355-62.

80. Kansal K, Yang Z, Fishman AM, Sair HI, Ying SH, Jedynak BM, et al. Structural cerebellar correlates of cognitive and motor dysfunctions in cerebellar degeneration. Brain. 2017;140:707-20.

81. Gellersen HM, Guo CC, O'Callaghan C, Tan RH, Sami S, Hornberger M. Cerebellar atrophy in neurodegeneration - a meta-analysis. J Neurol Neurosurg Psychiatry. 2017;88:780-8.

82. Sang L, Qin W, Liu Y, Han W, Zhang Y, Jiang T, et al. Restingstate functional connectivity of the vermal and hemispheric subregions of the cerebellum with both the cerebral cortical networks and subcortical structures. Neuroimage. 2012;61:1213-25.

83. Küper M, Hermsdörfer J, Brandauer B, Thürling M, Schoch B, Theysohn N, et al. Lesions of the dentate and interposed nuclei are associated with impaired prehension in cerebellar patients. Neurosci Lett. 2011;499:132-6.

84. Glickstein M, Gerrits N, Kralj-Hans I, Mercier B, Stein J, Voogd J. Visual pontocerebellar projections in the macaque. J Comp Neurol. 1994;349:51-72.

85. Glickstein M, Sultan F, Voogd J. Functional localization in the cerebellum. Cortex. 2011;47:59-80.

86. Chen SHA, Desmond JE. Cerebrocerebellar networks during articulatory rehearsal and verbal working memory tasks. Neuroimage. 2005;24:332-8.

87. Stoodley CJ. The cerebellum and cognition: evidence from functional imaging studies. Cerebellum. 2012;11:352-65.
88. Van Overwalle F, Baetens K, Mariën P, Vandekerckhove M. Social cognition and the cerebellum: a meta-analysis of over 350 fMRI studies. Neuroimage. 2014;86:554-72.

89. Rastogi A, Cash R, Dunlop K, Vesia M, Kucyi A, Ghahremani A, et al. Modulation of cognitive cerebello-cerebral functional connectivity by lateral cerebellar continuous theta burst stimulation. Neuroimage. 2017;158:48-57.

90. D'Mello AM, Turkeltaub PE, Stoodley CJ. Cerebellar tDCS modulates neural circuits during semantic prediction: a combined tDCS-fMRI study. J Neurosci. 2017;37:1604-13.

91. Stoodley CJ, Schmahmann JD. Evidence for topographic organization in the cerebellum of motor control versus cognitive and affective processing. Cortex. 2010;46:831-44.

92. Price CJ. A review and synthesis of the first 20 years of PET and fMRI studies of heard speech, spoken language and reading. Neuroimage. 2012;62:816-47.

93. Mariën P, Ackermann H, Adamaszek M, Barwood CHS, Beaton A, Desmond J, et al. Consensus paper: language and the cerebellum: an ongoing enigma. Cerebellum. 2014;13:386-410.

94. Turkeltaub PE, Swears MK, D'Mello AM, Stoodley CJ. Cerebellar tDCS as a novel treatment for aphasia? Evidence from behavioral and resting-state functional connectivity data in healthy adults. Restor Neurol Neurosci. 2016;34:491-505.

95. Lesage E, Morgan BE, Olson AC, Meyer AS, Miall RC. Cerebellar rTMS disrupts predictive language processing. Curr Biol. 2012;22.

96. Miall RCC, Antony J, Goldsmith-Sumner A, Harding SRR, McGovern C, Winter JLL. Modulation of linguistic prediction by TDCS of the right lateral cerebellum. Neuropsychologia. 2016;86:103-9.

97. Stoodley CJ, Schmahmann JD. Functional linguistic topography of the cerebellum. In: Manto M, Mariën P, editors. Linguist cerebellum. Elsevier; 2016. p. 315-335.

98. Van Overwalle F, Baetens K, Mariën P, Vandekerckhove M. Cerebellar areas dedicated to social cognition? A comparison of meta-analytic and connectivity results. Soc Neurosci. 2015;10: $337-44$.

99. Van Overwalle F, D'aes T, Mariën P. Social cognition and the cerebellum: a meta-analytic connectivity analysis. Hum Brain Mapp. 2015;36:5137-54.

100. Van Overwalle F, Mariën P. Functional connectivity between the cerebrum and cerebellum in social cognition: a multi-study analysis. Neuroimage. 2016;124:248-55.

101. Gamond L, Ferrari C, La Rocca S, Cattaneo Z. Dorsomedial prefrontal cortex and cerebellar contribution to in-group attitudes: a transcranial magnetic stimulation study. Eur J Neurosci. 2017;45: 932-9.

102. Stoodley CJ, Limperopoulos C. Structure-function relationships in the developing cerebellum: evidence from early-life cerebellar injury and neurodevelopmental disorders. Semin Fetal Neonatal Med. 2016;21:356-64.

103. Koppelmans V, Hoogendam YY, Hirsiger S, Mérillat S, Jäncke L, Seidler RD. Regional cerebellar volumetric correlates of manual motor and cognitive function. Brain Struct Funct. 2017;222:1929-44.

104. Olivito G, Cercignani M, Lupo M, Iacobacci C, Clausi S, Romano $\mathrm{S}$, et al. Neural substrates of motor and cognitive dysfunctions in SCA2 patients: a network based statistics analysis. NeuroImage Clin. 2017;14:719-25.

105. Pereira L, Airan RD, Fishman A, Pillai JJ, Kansal K, Onyike CU, et al. Resting-state functional connectivity and cognitive dysfunction correlations in spinocerebelellar ataxia type 6 (SCA6). Human brain mapping. 2017; 38(6): 3001-3010.

106. Adamaszek M, D'Agata F, Kirkby KC, Trenner MU, Sehm B, Steele CJ, et al. Impairment of emotional facial expression and prosody discrimination due to ischemic cerebellar lesions. Cerebellum. 2014;13:338-45. 
107. Adamaszek M, D'Agata F, Steele CJ, Sehm B, Schoppe C, Strecker K, et al. Comparison of visual and auditory emotion recognition in patients with cerebellar and Parkinson's disease. Soc Neurosci. 2018:1-13.

108. D’Agata F, Caroppo P, Baudino B, Caglio M, Croce M, Bergui M, et al. The recognition of facial emotions in spinocerebellar ataxia patients. Cerebellum. 2011;10:600-10.

109. Hoche F, Guell X, Sherman JC, Vangel MG, Schmahmann JD. Cerebellar contribution to social cognition. Cerebellum. 2016;15: 732-43.

110. Clausi S, Iacobacci C, Lupo M, Olivito G, Molinari M, Leggio M. The role of the cerebellum in unconscious and conscious processing of emotions: a review. Appl Sci. 2017;7:521.

111. Cattaneo L, Fasanelli M, Andreatta O, Bonifati DM, Barchiesi G, Caruana F. Your actions in my cerebellum: subclinical deficits in action observation in patients with unilateral chronic cerebellar stroke. Cerebellum. 2012;11:264-71.

112. Leggio MG, Tedesco AM, Chiricozzi FR, Clausi S, Orsini A, Molinari M. Cognitive sequencing impairment in patients with focal or atrophic cerebellar damage. Brain. 2008;131:1332-43.

113. Van Overwalle F, De Coninck S, Heleven E, Perrotta G, Taib NO, Manto M, Mariën P. The role of the cerebellum in reconstructing social action sequences: a pilot study. Social cognitive and affective neuroscience. 2019; 30;14(5):549-58.

114. Zalla T, Labruyère N, Clément $A$, Georgieff N. Predicting ensuing actions in children and adolescents with autism spectrum disorders. Exp Brain Res. 2010;201:809-19.

115. Zalla T, Labruyere N, Georgieff N. Goal-directed action representation in autism. J Autism Dev Disord. 2006;36:527-40.

116. Wang SSH, Kloth AD, Badura A. The cerebellum, sensitive periods, and autism. Neuron. 2014;83:518-32.

117. Becker EBE, Stoodley CJ. Autism spectrum disorder and the cerebellum. Int Rev Neurobiol. 2013;113:1-34.

118. D'Mello AM, Stoodley CJ. Cerebro-cerebellar circuits in autism spectrum disorder. Front Neurosci. 2015;9:408.

119. Olivito G, Clausi S, Laghi F, Tedesco AM, Baiocco R, Mastropasqua $\mathrm{C}$, et al. Resting-state functional connectivity changes between dentate nucleus and cortical social brain regions in autism spectrum disorders. Cerebellum. 2017;16:283-92.

120. Jack A, Morris JP. Neocerebellar contributions to social perception in adolescents with autism spectrum disorder. Dev Cogn Neurosci. 2014; 10:77-92.

121. D'Mello AM, Crocetti D, Mostofsky SH, Stoodley CJ. Cerebellar gray matter and lobular volumes correlate with core autism symptoms. NeuroImage Clin. 2015;7:631-9.

122. Ito M. Control of mental activities by internal models in the cerebellum. Nat Rev Neurosci. 2008;9:304-13.

123. Schmahmann JD. Disorders of the cerebellum: ataxia, dysmetria of thought, and the cerebellar cognitive affective syndrome. J Neuropsychiatr Clin Neurosci. 2004;16:367-78.

124. Miall RC. The cerebellum, predictive control and motor coordination. Novartis Found Symp. 1998;218:272-84 discussion 284-90.

125. Sokolov AA, Miall RC, Ivry RB. The cerebellum: adaptive prediction for movement and cognition. Trends Cogn Sci. 2017;21: 313-32.

126. Peterburs J, Desmond JE. The role of the human cerebellum in performance monitoring. Curr Opin Neurobiol. 2016:40:38-44.

127. Pleger B, Timmann D. The role of the human cerebellum in linguistic prediction, word generation and verbal working memory: evidence from brain imaging, non-invasive cerebellar stimulation and lesion studies. Neuropsychologia. 2018;115:204-10.

128. Argyropoulos GPD. The cerebellum, internal models and prediction in 'non-motor' aspects of language: a critical review. Brain Lang. 2016;161:4-17.
129. Moberget T, Gullesen EH, Andersson S, Ivry RB, Endestad T. Generalized role for the cerebellum in encoding internal models: evidence from semantic processing. J Neurosci. 2014;34:2871-8.

130. Lesage E, Hansen PC, Miall RC. Right lateral cerebellum represents linguistic predictability. J Neurosci. 2017;37:6231-41.

131. Bakker M, Allum JHJ, Visser JE, Grüneberg C, van de Warrenburg BP, Kremer BHP, et al. Postural responses to multidirectional stance perturbations in cerebellar ataxia. Exp Neurol. 2006;202:21-35.

132. Ghez C, Thach WT. The cerebellum. In: Kandel ER, Schwartz JH, Jessell TM, editors. Principles of neuroscience. 5th ed. New York: McGraw-Hill; 2000. p. 832-52.

133. Ilg W, Golla H, Thier P, Giese MA. Specific influences of cerebellar dysfunctions on gait. Brain. 2007;130:786-98.

134. Marsden J, Harris C. Cerebellar ataxia: pathophysiology and rehabilitation. Clin Rehabil. 2011;25:195-216.

135. Bultmann U, Pierscianek D, Gizewski ER, Schoch B, Fritsche N, Timmann D, et al. Functional recovery and rehabilitation of postural impairment and gait ataxia in patients with acute cerebellar stroke. Gait Posture. 2014;39:563-9.

136. Milne SC, Corben LA, Georgiou-Karistianis N, Delatycki MB, Yiu EM. Rehabilitation for individuals with genetic degenerative ataxia: a systematic review. Neurorehabil Neural Repair. 2017;31: 609-22.

137. Mills RJ, Yap L, Young CA. Treatment for ataxia in multiple sclerosis. Cochrane Database Syst Rev. 2007.

138. Martin CL, Tan D, Bragge P, Bialocerkowski A. Effectiveness of physiotherapy for adults with cerebellar dysfunction: a systematic review. Clin Rehabil. 2009;23:15-26.

139. Kaut O, Jacobi H, Coch C, Prochnicki A, Minnerop M, Klockgether T, et al. A randomized pilot study of stochastic vibration therapy in spinocerebellar ataxia. Cerebellum. 2014;13: 237-42.

140. Keller JL, Bastian AJ. A home balance exercise program improves walking in people with cerebellar ataxia. Neurorehabil Neural Repair. 2014;28:770-8.

141. DeLuca J, Nocentini U. Neuropsychological, medical and rehabilitative management of persons with multiple sclerosis. NeuroRehabilitation. 2011;29:197-219.

142. Kelly PJ, Stein J, Shafqat S, Eskey C, Doherty D, Chang Y, et al. Functional recovery after rehabilitation for cerebellar stroke. Stroke. 2001;32:530-4.

143. Morton SM, Bastian AJ. Mechanisms of cerebellar gait ataxia. Cerebellum. 2007;6:79-86.

144. Palesi F, De Rinaldis A, Castellazzi G, Calamante F, Muhlert N, Chard D, et al. Contralateral cortico-ponto-cerebellar pathways reconstruction in humans in vivo: implications for reciprocal cerebro-cerebellar structural connectivity in motor and nonmotor areas. Sci Rep. 2017;7.

145. Farzan F, Pascual-Leone A, Schmahmann JD, Halko M Enhancing the temporal complexity of distributed brain networks with patterned cerebellar stimulation. Sci Rep. 2016;6.

146. Dalal SS, Baillet S, Adam C, Ducorps A, Schwartz D, Jerbi K, et al. Simultaneous MEG and intracranial EEG recordings during attentive reading. Neuroimage. 2009;45:1289-304.

147. Hausen HS, Lachmann EA, Nagler W. Cerebral diaschisis following cerebellar hemorrhage. Arch Phys Med Rehabil. 1997;78: 546-8.

148. Silveri MC, Misciagna S, Terrezza G. Right side neglect in right cerebellar lesion. J Neurol Neurosurg Psychiatry. 2001;71:114-7.

149. Wessel K, Nitschke MF. Cerebellar somatotopic representation and cerebro-cerebellar interconnections in ataxic patients. Prog Brain Res. 1997;114:577-88.

150. Torriero S, Oliveri M, Koch G, Lo Gerfo E, Salerno S, Petrosini L, et al. Cortical networks of procedural learning: evidence from cerebellar damage. Neuropsychologia. 2007;45:1208-14. 
151. Ptak R, Schnider A. Neuropsychological rehabilitation of higher cortical functions after brain damage. In: Dietz V, Ward NS, editors. Oxford textbook of neurorehabilitation (OTs in clinical neurology). New York, NY: Oxford University Press; 2015. p. 262-71.

152. Pope PA, Chris MR. Restoring cognitive functions using noninvasive brain stimulation techniques in patients with cerebellar disorders. Front Psychiatry. 2014;5.

153. Robertson IH, Fitzpatrick SM. The future of cognitive neurorehabilitation. In: Stuss DT, Winocur G, Robertson IH, editors. Cognitive neurorehabilitation. Second ed. Cambridge University Press, Cambridge; 2008. p. 565-74.

154. van Dun K, Van Overwalle F, Manto M, Marien P. Cognitive impact of cerebellar damage: is there a future for cognitive rehabilitation? CNS Neurol Disord Drug Targets. 2018;

155. Manto M, Jacquy J, Hildebrand J, Godaux E. Recovery of hypermetria after a cerebellar stroke occurs as a multistage process. Ann Neurol. 1995;38:437-45.

156. Schmahmann J. The cerebellum and cognition. Int Rev Neurobiol. 1997;41.

157. Schmahmann JD. The cerebellum and cognition. Neurosci Lett. 2019;688:62-75.

158. Brissenden JA, Tobyne SM, Osher DE, Levin EJ, Halko MA, Somers DC. Topographic cortico-cerebellar networks revealed by visual attention and working memory. Curr Biol. 2018;28: 3364-3372.e5.

159. Schmahmann JD, Pandya DN. Fiber pathways of the brain. New York: Oxford University Press; 2006.

160. Schmahmann JD, Pandya DN. Disconnection syndromes of basal ganglia, thalamus, and cerebrocerebellar systems. Cortex. 2008;44:1037-66.

161. Schmahmann JD, Pandya DN. The cerebrocerebellar system. Int Rev Neurobiol. 1997;41:31-60.

162. Adamaszek M, D’Agata F, Ferrucci R, Habas C, Keulen S, Kirkby $\mathrm{KC}$, et al. Consensus paper: cerebellum and emotion. Cerebellum. 2017;16:552-76.

163. Baumann O, Borra RJ, Bower JM, Cullen KE, Habas C, Ivry RB, et al. Consensus paper: the role of the cerebellum in perceptual processes. Cerebellum. 2015;14:197-220.

164. Molinari M, Leggio M. Cerebellum: cognitive functions. In: Wright JD, editor. International encyclopedia of the social and behavioral sciences. Second Ed. Elsevier; 2015. p. 327-31.

165. Leggio M. Clinical functional topography in cognition. In: Gruol DL, Koibuchi N, Manto M, Molinari M, Schmahmann JD, Shen Y, editors. Essentials of cerebellum and cerebellar disorders. A primer for graduate students. Springer International Publishing; 2016. p. 391-6.

166. Leggio M, Olivito G. Topography of the cerebellum in relation to social brain regions and emotions. Handb Clin Neurol. 2018;154: 71-84.

167. Schmahmann JD. Cognitive and behavioral manifestations of cerebellar strokes: their relation to motor control and functional topography in the cerebellum. In: Caplan LR, van Gijn J, editors. Stroke syndromes. Third ed. Cambridge: Cambridge University Press; 2012. p. 32-51.

168. Amarenco P, Roullet E, Goujon C, Chéron F, Hauw JJ, Bousser MG. Infarction in the anterior rostral cerebellum (the territory of the lateral branch of the superior cerebellar artery). Neurology. 1991;41:253-8.

169. Chaves CJ, Caplan LR, Chung CS, Tapia J, Amarenco P, Teal P, et al. Cerebellar infarcts in the New England Medical Center Posterior Circulation Stroke Registry. Neurology. 1994;44:1385-90.

170. Kase CS, White JL, Joslyn JN, Williams JP, Mohr JP. Cerebellar infarction in the superior cerebellar artery distribution. Neurology. 1985;35:705-11.
171. Milandre L, Broca P, Sambuc R, et al. Les crises épileptiques au décours des accidents cérébrovasculaires: analyse clinique de 78 cas. Rev Neurol. 1992;148:767-72.

172. Barth A, Bogousslavsky J, Regli F. The clinical and topographic spectrum of cerebellar infarcts: a clinical magnetic resonance imaging correlation study. Ann Neurol. 1993;33:451-6.

173. Terao S, Sobue G, Izumi M, Miura N, Takeda A, Mitsuma T. Infarction of superior cerebellar artery presenting as cerebellar symptoms. Stroke. 1996;27:1679-81.

174. Botez-Marquard T, Léveillé J, Botez MI. Neuropsychological functioning in unilateral cerebellar damage. Can J Neurol Sci. 1994;21:353-7.

175. Stoodley CJ, Valera EM, Schmahmann JD. An fMRI study of intra-individual functional topography in the human cerebellum. Behav Neurol. 2010;23:65-79.

176. Fiez JA, Petersen SE, Cheney MK, Raichle ME. Impaired nonmotor learning and error detection associated with cerebellar damage. A single case study. Brain. 1992;115:155-78.

177. Silveri MC, Leggio MG, Molinari M. The cerebellum contributes to linguistic production: a case of agrammatic speech following a right cerebellar lesion. Neurology. 1994;44:2047-50.

178. Malm J, Kristensen B, Karlsson T, Carlberg B, Fagerlund M, Olsson T. Cognitive impairment in young adults with infratentorial infarcts. Neurology. 1998;51:433-40.

179. Neau JP, Arroyo-Anllo E, Bonnaud V, Ingrand P, Gil R, Anllo EA, et al. Neuropsychological disturbances in cerebellar infarcts. Acta Neurol Scand. 2000;102:363-70.

180. Exner C, Weniger G, Irle E. Cerebellar lesions in the PICA but not SCA territory impair cognition. Neurology. 2004;63:2132-5.

181. Hoffmann M, Schmitt F. Cognitive impairment in isolated subtentorial stroke. Acta Neurol Scand. 2004;109:14-24.

182. Hoffmann M, Cases LB. Etiology of frontal network syndromes in isolated subtentorial stroke. Behav Neurol. 2008;20:101-5.

183. Kalashnikova LA, Zueva YV, Pugacheva OV, Korsakova NK. Cognitive impairments in cerebellar infarcts. Neurosci Behav Physiol. 2005;35:773-9.

184. Hokkanen LSK, Kauranen V, Roine RO, Salonen O, Kotila M. Subtle cognitive deficits after cerebellar infarcts. Eur J Neurol. 2006;13:161-70.

185. Leggio MG, Silveri MC, Petrosini L, Molinari M. Phonological grouping is specifically affected in cerebellar patients: a verbal fluency study. J Neurol Neurosurg Psychiatry. 2000;69:102-6.

186. Stoodley CJ, Schmahmann JD. The cerebellum and language: evidence from patients with cerebellar degeneration. Brain Lang. 2009;110:149-53.

187. Richter S, Aslan B, Gerwig M, Wilhelm H, Kramer S, Todica O, et al. Patients with chronic focal cerebellar lesions show no cognitive abnormalities in a bedside test. Neurocase. 2007;13:25-36.

188. Schweizer TA, Alexander MP, Susan Gillingham BA, Cusimano M, Stuss DT. Lateralized cerebellar contributions to word generation: a phonemic and semantic fluency study. Behav Neurol. 2010;23:31-7.

189. Alexander MP, Gillingham S, Schweizer T, Stuss DT. Cognitive impairments due to focal cerebellar injuries in adults. Cortex. 2012;48:980-90.

190. Manes F, Villamil AR, Ameriso S, Roca M, Torralva T. "Real life" executive deficits in patients with focal vascular lesions affecting the cerebellum. J Neurol Sci. 2009;283:95-8.

191. Ravizza SM, McCormick C, Schlerf JE, Justus T, Ivry RB, Fiez J. Cerebellar damage produces selective deficits in verbal working memory. Brain. 2006;129:306-20.

192. Ziemus B, Baumann O, Luerding R, Schlosser R, Schuierer G, Bogdahn $U$, et al. Impaired working-memory after cerebellar infarcts paralleled by changes in BOLD signal of a cortico-cerebellar circuit. Neuropsychologia. 2007;45:2016-24. 
193. Silveri MC, Di Betta AM, Filippini V, Leggio MG, Molinari M. Verbal short-term store-rehearsal system and the cerebellum. Evidence from a patient with a right cerebellar lesion. Brain. 1998;121(Pt 1):2175-87.

194. Chiricozzi FR, Clausi S, Molinari M, Leggio MG. Phonological short-term store impairment after cerebellar lesion: a single case study. Neuropsychologia. 2008;46:1940-53.

195. Greve KW, Stanford MS, Sutton C, Foundas AL. Cognitive and emotional sequelae of cerebellar infarct: a case report. Arch Clin Neuropsychol. 1999;14:455-69.

196. Vokaer M, Bier JC, Elincx S, Claes T, Paquier P, Goldman S, et al. The cerebellum may be directly involved in cognitive functions. Neurology. 2002;58:967-70.

197. Paulus KS, Magnano I, Conti M, Galistu P, D’Onofrio M, Satta W, et al. Pure post-stroke cerebellar cognitive affective syndrome: a case report. Neurol Sci. 2004;25:220-4.

198. Maeshima S, Osawa A. Stroke rehabilitation in a patient with cerebellar cognitive affective syndrome. Brain Inj. 2007;21:877-83.

199. Mariën P, Baillieux H, De Smet HJ, Engelborghs S, Wilssens I, Paquier P, et al. Cognitive, linguistic and affective disturbances following a right superior cerebellar artery infarction: a case study. Cortex. 2009;45:527-36.

200. Silveri MC, Misciagna S, Leggio MG, Molinari M. Spatial dysgraphia and cerebellar lesion: a case report. Neurology. 1997;48:1529-32.

201. Annoni J-MM, Ptak R, Caldara-Schnetzer A-SS, Khateb A, Pollermann BZ. Decoupling of autonomic and cognitive emotional reactions after cerebellar stroke. Ann Neurol. 2003;53:654-8.

202. Lagarde J, Hantkie O, Hajjioui A, Yelnik A. Neuropsychological disorders induced by cerebellar damage. Ann Phys Rehabil Med. 2009:52:360-70.

203. Steinlin M. The cerebellum in cognitive processes: supporting studies in children. Cerebellum. 2007;6:237-41.

204. Geschwind DH. Focusing attention on cognitive impairment in spinocerebellar ataxia. Arch Neurol. 1999;56:20-2.

205. Orsi L, D'Agata F, Caroppo P, Franco A, Caglio MM, Avidano F, et al. Neuropsychological picture of 33 spinocerebellar ataxia cases. J Clin Exp Neuropsychol. 2011;33:315-25.

206. Roeske S, Filla I, Heim S, Amunts K, Helmstaedter C, Wüllner U, et al. Progressive cognitive dysfunction in spinocerebellar ataxia type 3. Mov Disord. 2013;28:1435-8.

207. Lindsay E, Storey S. Cognitive changes in the spinocerebellar ataxias due to expanded polyglutamine tracts: a survey of the literature. Brain Sci. 2017;7:1-20.

208. Bottini AR, Gatti RA, Wirenfeldt M, Vinters HV. Heterotopic Purkinje cells in ataxia-telangiectasia. Neuropathology. 2012;32: 23-9.

209. Hoche F, Frankenberg E, Rambow J, Theis M, Harding JA, Qirshi $\mathrm{M}$, et al. Cognitive phenotype in ataxia-telangiectasia. Pediatr Neurol. 2014;51:297-310.

210. Hoche F, Daly MP, Chutake YK, Valera E, Sherman JC, Schmahmann JD. The cerebellar cognitive affective syndrome in ataxia-telangiectasia. Cerebellum. 2018;

211. Laforce R, Buteau JP, Bouchard JP, Rouleau GA, Bouchard RW, Dupré N. Cognitive impairment in ARCA-1, a newly discovered pure cerebellar ataxia syndrome. Cerebellum. 2010;9:443-53.

212. Botez-Marquard T, Botez MI. Cognitive behavior in heredodegenerative ataxias. Eur Neurol. 1993;33:351-7.

213. Dogan I, Tinnemann E, Romanzetti S, Mirzazade S, Costa AS, Werner CJ, et al. Cognition in Friedreich's ataxia: a behavioral and multimodal imaging study. Ann Clin Transl Neurol. 2016;3:572-87.

214. Olivito G, Lupo M, Iacobacci C, Clausi S, Romano S, Masciullo $\mathrm{M}$, et al. Structural cerebellar correlates of cognitive functions in spinocerebellar ataxia type 2. J Neurol. 2018;265:597-606.

215. Olivito G, Lupo M, Iacobacci C, Clausi S, Romano S, Masciullo $\mathrm{M}$, et al. Microstructural MRI basis of the cognitive functions in patients with spinocerebellar ataxia type 2 . Neuroscience. 2017;366:44-53.

216. Halko MA, Farzan F, Eldaief MC, Schmahmann JD, PascualLeone A. Intermittent theta-burst stimulation of the lateral cerebellum increases functional connectivity of the default network. J Neurosci. 2014;34:12049-56.

217. Brady RO, Gonsalvez I, Lee I, Öngür D, Seidman LJ, Schmahmann JD, et al. Cerebellar-prefrontal network connectivity and negative symptoms in schizophrenia. Am J Psychiatry. 2019;

218. Mariën P, Beaton A. The enigmatic linguistic cerebellum: clinical relevance and unanswered questions on nonmotor speech and language deficits in cerebellar disorders. Cerebellum \& Ataxias. 2014;1:12.

219. Wiig E, Secord W. Test of language competence-expanded edition. 1st edition. San Antonio: Pearson; 1989.

220. Guell X, Hoche F, Schmahmann JD. Metalinguistic deficits in patients with cerebellar dysfunction: empirical support for the dysmetria of thought theory. Cerebellum. 2015;14:50-8.

221. Haarmeier T, Thier P. The attentive cerebellum - myth or reality? Cerebellum. 2007;6:177-83.

222. Lupo M, Troisi E, Chiricozzi FR, Clausi S, Molinari M, Leggio M. Inability to process negative emotions in cerebellar damage: a functional transcranial Doppler sonographic study. Cerebellum. 2015;14:663-9.

223. Brissenden JA, Levin EJ, Osher DE, Halko MA, Somers DC. Functional evidence for a cerebellar node of the dorsal attention network. J Neurosci. 2016;36:6083-96.

224. Leggio MG, Chiricozzi FR, Clausi S, Tedesco AM, Molinari M. The neuropsychological profile of cerebellar damage: the sequencing hypothesis. Cortex. 2011;47:137-44.

225. Leggio M, Molinari M. Cerebellar sequencing: a trick for predicting the future. Cerebellum. 2015;14:35-8.

226. Molinari M, Chiricozzi FR, Clausi S, Tedesco AM, De Lisa M, Leggio MG. Cerebellum and detection of sequences, from perception to cognition. Cerebellum. 2008;7:611-5.

227. Molinari M, Leggio MG, Silveri MC. Verbal fluency and agrammatism. Int Rev Neurobiol. 1997;41:325-39.

228. Shin JC, Ivry RB. Spatial and temporal sequence learning in patients with Parkinson's disease or cerebellar lesions. J Cogn Neurosci. 2003;15:1232-43.

229. Frings M, Boenisch R, Gerwig M, Diener HC, Timmann D. Learning of sensory sequences in cerebellar patients. Learn Mem. 2004;11:347-55.

230. Frings M, Maschke M, Gerwig M, Diener HC, Timmann D. Acquisition of simple auditory and visual sequences in cerebellar patients. Cerebellum. 2006;5:206-11.

231. Richter S, Kaiser O, Hein-Kropp C, Dimitrova A, Gizewski E, Beck A, et al. Preserved verb generation in patients with cerebellar atrophy. Neuropsychologia. 2004;42:1235-46.

232. Timmann D, Drepper J, Calabrese S, Bürgerhoff K, Maschke M, Kolb FP, et al. Use of sequence information in associative learning in control subjects and cerebellar patients. Cerebellum. 2004;3: 75-82.

233. Restuccia D, Della M, G, Valeriani M, Leggio MG, Molinari M. Cerebellar damage impairs detection of somatosensory input changes. A somatosensory mismatch-negativity study. Brain. 2007;130:276-87.

234. Kossorotoff M, Gonin-Flambois C, Gitiaux C, Quijano S, Boddaert N, Bahi-Buisson N, et al. A cognitive and affective pattern in posterior fossa strokes in children: a case series. Dev Med Child Neurol. 2010;52:626-31.

235. Karatekin C, Lazareff JA, Asarnow RF. Relevance of the cerebellar hemispheres for executive functions. Pediatr Neurol. 2000;22: 106-12.

236. Grill J, Viguier D, Kieffer V, Bulteau C, Sainte-Rose C, Hartmann $\mathrm{O}$, et al. Critical risk factors for intellectual impairment in children 
with posterior fossa tumors: the role of cerebellar damage. $\mathrm{J}$ Neurosurg Pediatr. 2004;101:152-8.

237. Turkel SB, Shu Chen L, Nelson MD, Hyder D, Gilles FH, Woodall L, et al. Case series: acute mood symptoms associated with posterior fossa lesions in children. J Neuropsychiatr Clin Neurosci. 2004;16:443-5.

238. Berger A, Tzur G, Constantini S, Sadeh M, Shuper A, Kornreich L, et al. Task switching after cerebellar damage. Neuropsychology. 2005;19:362-70.

239. Vaquero E, Gómez CM, Quintero EA, González-Rosa JJ, Márquez J. Differential prefrontal-like deficit in children after cerebellar astrocytoma and medulloblastoma tumor. Behav Brain Funct. 2008;4:18.

240. Scott RB, Stoodley CJ, Anslow P, Paul C, Stein JF, Sugden EM, et al. Lateralized cognitive deficits in children following cerebellar lesions. Dev Med Child Neurol. 2007;43:685-91.

241. Rønning C, Sundet K, Due-Tønnessen B, Lundar T, Helseth E. Persistent cognitive dysfunction secondary to cerebellar injury in patients treated for posterior fossa tumors in childhood. Pediatr Neurosurg. 2005;41:15-21.

242. Gottwald B, Wilde B, Mihajlovic Z, Mehdorn HM. Evidence for distinct cognitive deficits after focal cerebellar lesions. J Neurol Neurosurg Psychiatry. 2004;75:1524-31.

243. Gross-Tsur V, Ben-Bashat D, Shalev RS, Levav M, Sira LB. Evidence of a developmental cerebello-cerebral disorder. Neuropsychologia. 2006;44:2569-72.

244. Maryniak A, Roszkowski M. Cognitive and affective disturbances in children after surgical treatment of cerebellar tumors. Neurol Neurochir Pol. 2005;39:202-6.

245. Richter S, Dimitrova A, Maschke M, Gizewski E, Beck A, Aurich $\mathrm{V}$, et al. Degree of cerebellar ataxia correlates with threedimensional MRI-based cerebellar volume in pure cerebellar degeneration. Eur Neurol. 2005;54:23-7.

246. Wisoff JH, Epstein FJ. Pseudobulbar palsy after posterior fossa operation in children. Neurosurgery. 1984;15:707-9.

247. Rekate HL, Grubb RL, Aram DM, Hahn JF, Ratcheson RA. Muteness of cerebellar origin. Arch Neurol American Medical Association. 1985;42:697-8.

248. Catsman-Berrevoets CE, Dongen HR, Van Zwetsloot CP. Transient loss of speech followed by dysarthria after removal of posterior fossa tumour. Dev Med Child Neurol. 2008;34:1102-9.

249. Kingma A, Mooij JJA, Metzemaekers JDM, Leeuw JA. Transient mutism and speech disorders after posterior fossa surgery in children with brain tumours. Acta Neurochir. 1994;131:74-9.

250. Dietze DD Jr, Mickle JP. Cerebellar mutism after posterior fossa surgery. Pediatr Neurosurg. 1990;16:25-31.

251. van Dongen HR, Catsman-Berrevoets CE, van Mourik M. The syndrome of "cerebellar" mutism and subsequent dysarthria. Neurology. 1994;44:2040-6.

252. Pollack IF, Polinko P, Albright LA, Towbin R, Fitz C. Mutism and pseudobulbar symptoms after resection of posterior fossa tumors in children: incidence and pathophysiology. Neurosurgery. 1995;37:885-93.

253. Sadeh M, Cohen I. Transient loss of speech after removal of posterior fossa tumors - one aspect of a larger neuropsychological entity: the cerebellar cognitive affective syndrome. Pediatr Hematol Oncol. 2001;18:423-6.

254. Gudrunardottir T, Morgan AT, Lux AL, Walker DA, Walsh KS, Wells EM, et al. Consensus paper on post-operative pediatric cerebellar mutism syndrome: the Iceland Delphi results. Childs Nerv Syst. 2016;32(7):1195-203.

255. Baillieux H, Weyns F, Paquier P, De Deyn PP, Mariën P. Posterior fossa syndrome after a vermian stroke: a new case and review of the literature. Pediatr Neurosurg. 2007;43:386-95.
256. Mariën P, De Smet HJ, Wijgerde E, Verhoeven J, Crols R, De Deyn PP. Posterior fossa syndrome in adults: a new case and comprehensive survey of the literature. Cortex. 2013;49:284-300.

257. Limperopoulos C, Soul JS, Haidar H, Huppi PS, Bassan H, Warfield SK, et al. Impaired trophic interactions between the cerebellum and the cerebrum among preterm infants. Pediatrics. 2005;116:844-50.

258. Limperopoulos C, Bassan H, Gauvreau K, Robertson RL, Sullivan NR, Benson CB, et al. Does cerebellar injury in premature infants contribute to the high prevalence of long-term cognitive, learning, and behavioral disability in survivors? Pediatrics. 2007;120:584-93.

259. Wingeier K, Bigi S, El-Koussy M, Heinks-Maldonado T, Boltshauser E, Steinlin M. Long-term sequelae after acquired pediatric hemorrhagic cerebellar lesions. Childs Nerv Syst. 2011;27: 923-31.

260. Hickey CL, Sherman JC, Goldenberg P, Kritzer A, Caruso P, Schmahmann JD, et al. Cerebellar cognitive affective syndrome: insights from Joubert syndrome. Cerebellum \& Ataxias. 2018;5:5.

261. Lupo M, Olivito G, Siciliano L, Masciullo M, Bozzali M, Molinari $\mathrm{M}$, et al. Development of a psychiatric disorder linked to cerebellar lesions. Cerebellum. 2018;17:438-46.

262. Brossard-Racine M, du Plessis AJ, Limperopoulos C. Developmental cerebellar cognitive affective syndrome in expreterm survivors following cerebellar injury. Cerebellum. 2015;14:151-64.

263. Pollack IF. Posterior fossa syndrome. Int Rev Neurobiol. 1997;41: 411-32.

264. Clausi S, Coricelli G, Pisotta I, Pavone EF, Lauriola M, Molinari $\mathrm{M}$, et al. Cerebellar damage impairs the self-rating of regret feeling in a gambling task. Front Behav Neurosci. 2015;9.

265. Turkel SB, Brumm VL, Mitchell WG, Tavare CJ. Mood and behavioral dysfunction with opsoclonus-myoclonus ataxia. J Neuropsychiatr Clin Neurosci. 2006;18:239-41.

266. Gorman MP. Update on diagnosis, treatment, and prognosis in opsoclonus-myoclonus-ataxia syndrome. Curr Opin Pediatr. 2010;22:745-50

267. Baillieux H, De Smet HJ, Lesage G, Paquier P, De Deyn PP, Mariën P. Neurobehavioral alterations in an adolescent following posterior fossa tumor resection. Cerebellum. 2006;5:289-95.

268. Lo RY, Figueroa KP, Pulst SM, Perlman S, Wilmot G, Gomez C, et al. Depression and clinical progression in spinocerebellar ataxias. Parkinsonism Relat Disord. 2016;22:87-92.

269. Bauman M, Kemper TL. Histoanatomic observations of the brain in early infantile autism. Neurology. 1985;35:866-74.

270. Moberget T, Doan NT, Alnæs D, Kaufmann T, Córdova-Palomera A, Lagerberg TV, et al. Cerebellar volume and cerebellocerebral structural covariance in schizophrenia: a multisite mega-analysis of 983 patients and 1349 healthy controls. Mol Psychiatry. 2018;23:1512-20.

271. Demirtas-Tatlidede A, Freitas C, Cromer JR, Safar L, Ongur D, Stone WS, et al. Safety and proof of principle study of cerebellar vermal theta burst stimulation in refractory schizophrenia. Schizophr Res. 2010;124:91-100.

272. Parker KL, Kim YC, Kelley RM, Nessler AJ, Chen KH, MullerEwald VA, et al. Delta-frequency stimulation of cerebellar projections can compensate for schizophrenia-related medial frontal dysfunction. Mol Psychiatry. 2017;22:647-55.

273. Tikka SK, Garg S, Sinha VK, Nizamie SH, Goyal N. Resting state dense array gamma oscillatory activity as a response marker for cerebellar-repetitive transcranial magnetic stimulation (rTMS) in schizophrenia. J ECT. 2015;31:258-62.

274. Garg S, Sinha VK, Tikka SK, Mishra P, Goyal N. The efficacy of cerebellar vermal deep high frequency (theta range) repetitive transcranial magnetic stimulation (rTMS) in schizophrenia: a 
randomized rater blind-sham controlled study. Psychiatry Res. 2016;243:413-20.

275. Chheda M, Sherman J, Schmahmann J. Neurologic, psychiatric and cognitive manifestations in cerebellar agenesis. Neurology. 2002;58:356.

276. Lupo M, Olivito G, Siciliano L, Masciullo M, Molinari M, Cercignani M, et al. Evidence of cerebellar involvement in the onset of a manic state. Front Neurol. 2018;9:774.

277. Olivito G, Lupo M, Laghi F, Clausi S, Baiocco R, Cercignani M, et al. Lobular patterns of cerebellar resting-state connectivity in adults with autism spectrum disorder. Eur J Neurosci. 2018;47: 729-35.

278. Stoodley CJ, D'Mello AM, Ellegood J, Jakkamsetti V, Liu P, Nebel MB, et al. Altered cerebellar connectivity in autism and cerebellar-mediated rescue of autism-related behaviors in mice. Nat Neurosci. 2017;20:1744-51.
279. Jalali R, Miall RC, Galea JM. No consistent effect of cerebellar transcranial direct current stimulation on visuomotor adaptation. J Neurophysiol. 2017;118:655-65.

280. Paulin MG. Neural representations of moving systems. Int Rev Neurobiol. 1997;41:515-33.

281. Voogd J, Shinoda Y, Ruigrok TJ, Sugihara I. Cerebellar nuclei and the inferior olivary nuclei: organization and connections. Handbook of the cerebellum and cerebellar disorders. 2013;377436.

282. Watson TC, Obiang P, Torres-Herraez A, Watilliaux A, Coulon P, Rochefort C, \& Rondi-Reig L. Anatomical and physiological foundations of cerebellohippocampal interaction. eLife. 2019; 8: e41896.

Publisher's Note Springer Nature remains neutral with regard to jurisdictional claims in published maps and institutional affiliations.

\section{Affiliations}

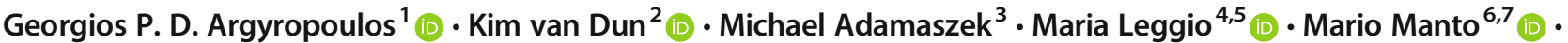 Marcella Masciullo ${ }^{8}$ (D) Marco Molinari ${ }^{9}$ (D) $\cdot$ Catherine J. Stoodley ${ }^{10}$ (D) $\cdot$ Frank Van Overwalle $^{11}$ (D) $\cdot$ Richard B. Ivry $^{12}$. Jeremy D. Schmahmann ${ }^{13}$}

1 Nuffield Department of Clinical Neurosciences, University of Oxford, Oxford, UK

2 Rehabilitation Research Center REVAL, UHasselt, Hasselt, Belgium

3 Clinical and Cognitive Neurorehabilitation, Center of Neurology and Neurorehabilitation, Klinik Bavaria Kreischa, An der Wolfsschlucht 1-2, 01703 Kreischa, Germany

4 Department of Psychology, Sapienza University of Rome, Rome, Italy

5 Ataxia Laboratory, IRCCS Fondazione Santa Lucia, Rome, Italy

6 Department of Neurology, CHU-Charleroi, 6000 Charleroi, Belgium

7 Department of Neurosciences, University of Mons, 7000 Mons, Belgium

8 SPInal REhabilitation Lab (SPIRE), IRCCS Fondazione Santa Lucia, Via Ardeatina 306, 00179 Rome, Italy
9 Neuro-Robot Rehabilitation Lab, IRCCS Fondazione Santa Lucia, Via Ardeatina 306, 00179 Rome, Italy

10 Department of Psychology, American University, Washington, DC 20016, USA

11 Department of Psychology, Vrije Universiteit Brussel, Brussels, Belgium

12 Department of Psychology, University of California, Berkeley, CA, USA

13 Ataxia Unit, Cognitive Behavioral Neurology Unit, Laboratory for Neuroanatomy and Cerebellar Neurobiology, Department of Neurology Massachusetts General Hospital, Harvard Medical School, Boston, MA, USA 